\title{
The Emerging Roles of the Calcineurin-Nuclear Factor of Activated T-Lymphocytes Pathway in Nervous System Functions and Diseases
}

\author{
Maulilio John Kipanyula, ${ }^{1}$ Wahabu Hamisi Kimaro, ${ }^{1}$ and Paul F. Seke Etet ${ }^{2}$ \\ ${ }^{1}$ Department of Veterinary Anatomy, Faculty of Veterinary Medicine, Sokoine University of Agriculture, P.O. Box 3016, \\ Chuo Kikuu, Morogoro, Tanzania \\ ${ }^{2}$ Department of Basic Health Sciences, Qassim University, Buraydah, Al-Qassim 51452, Saudi Arabia
}

Correspondence should be addressed to Maulilio John Kipanyula; kipanyula@suanet.ac.tz

Received 13 May 2016; Accepted 21 July 2016

Academic Editor: Elke Bromberg

Copyright (C) 2016 Maulilio John Kipanyula et al. This is an open access article distributed under the Creative Commons Attribution License, which permits unrestricted use, distribution, and reproduction in any medium, provided the original work is properly cited.

\begin{abstract}
The ongoing epidemics of metabolic diseases and increase in the older population have increased the incidences of neurodegenerative diseases. Evidence from murine and cell line models has implicated calcineurin-nuclear factor of activated T-lymphocytes (NFAT) signaling pathway, a $\mathrm{Ca}^{2+} /$ calmodulin-dependent major proinflammatory pathway, in the pathogenesis of these diseases. Neurotoxins such as amyloid- $\beta$, tau protein, and $\alpha$-synuclein trigger abnormal calcineurin/NFAT signaling activities. Additionally increased activities of endogenous regulators of calcineurin like plasma membrane $\mathrm{Ca}^{2+}$-ATPase (PMCA) and regulator of calcineurin 1 (RCAN1) also cause neuronal and glial loss and related functional alterations, in neurodegenerative diseases, psychotic disorders, epilepsy, and traumatic brain and spinal cord injuries. Treatment with calcineurin/NFAT inhibitors induces some degree of neuroprotection and decreased reactive gliosis in the central and peripheral nervous system. In this paper, we summarize and discuss the current understanding of the roles of calcineurin/NFAT signaling in physiology and pathologies of the adult and developing nervous system, with an emphasis on recent reports and cutting-edge findings. Calcineurin/NFAT signaling is known for its critical roles in the developing and adult nervous system. Its role in physiological and pathological processes is still controversial. However, available data suggest that its beneficial and detrimental effects are context-dependent. In view of recent reports calcineurin/NFAT signaling is likely to serve as a potential therapeutic target for neurodegenerative diseases and conditions. This review further highlights the need to characterize better all factors determining the outcome of calcineurin/NFAT signaling in diseases and the downstream targets mediating the beneficial and detrimental effects.
\end{abstract}

\section{Introduction}

Cellular responses to calcium $\left(\mathrm{Ca}^{2+}\right)$ mobilization are highly versatile due to the ability of intracellular $\mathrm{Ca}^{2+}$ signaling to activate an extensive repertoire of downstream signaling targets $[1,2]$. Among such molecules, the calmodulin- (CaM-) dependent phosphatase calcineurin and its transcription factors termed nuclear factors of activated T cells (NFATs) are reported as pivotal in a wide range of physiological processes, including homeostasis, angiogenesis, myogenesis, adipogenesis, osteogenesis, chondrocyte differentiation, cardiovascular system development, pancreatic $\beta$-cell proliferation, hair follicle cell differentiation and remodeling, and activities of cells of the immune and nervous systems [3-12]. Overexpressed and decreased activities of calcineurin/NFAT pathway were also reported in pathologies affecting these functions $[3,6,13-18]$.

A growing body of evidence suggests that calcineurin/ NFAT pathway plays critical roles in normal and pathological nervous system. Over the last decade, this signaling pathway was reported as major player in corticogenesis, synaptogenesis, and neuritogenesis during mammalian nervous system development [19-23], as well as myelination, synaptic plasticity, neurotransmission, and central and peripheral nervous system cell proliferation, migration, and differentiation in the mature nervous system [24-26]. Altered calcineurin/NFAT 
activation is increasingly linked to pathological features of neurodegenerative diseases such as amyotrophic lateral sclerosis, Huntington's, Parkinson's, and Alzheimer's diseases, characterized by massive synaptic dysfunction, glial activation, and neuronal death in some regions of the brain [2629]. Calcineurin/NFAT involvement has also been reported in psychiatric disorders, epilepsy, and traumatic brain and spinal cord injuries [30-35]. Moreover, recent data also suggest that NFAT isoforms are selectively activated in neurons and glial cells in nervous system diseases $[36,37]$ and animal models [38-41].

Herein, we discuss the current understanding of the role of calcineurin/NFAT signaling pathway in both physiology and pathologies of the adult and developing nervous system, with an emphasis on recent reports and cutting-edge findings.

\section{Calcineurin/NFAT Pathway}

2.1. Calcineurin. Calcineurin, also termed as protein phosphatase $\mathrm{B}$ (PP2B), is a $\mathrm{Ca}^{2+} / \mathrm{CaM}$-dependent serine/ threonine phosphatase. It was described for the first time in the bovine brain about 40 years ago $[42,43]$. Calcineurin is made up of a $61 \mathrm{kD}$ CaM-binding catalytic subunit termed calcineurin $\mathrm{A}(\mathrm{CnA})$ and a $19 \mathrm{kD} \mathrm{Ca}^{2+}$-binding regulatory subunit named calcineurin B ( $\mathrm{CnB})$ stably associated (noncovalently) [44, 45]. To date three isozymes of the catalytic subunit $(\operatorname{Cn} A \alpha, \operatorname{Cn} A \beta$, and $\operatorname{Cn} A \gamma)$ have been reported. There are two isoforms of the regulatory subunit, namely, $\mathrm{CnB} 1$ and $\mathrm{CnB} 2$. In vertebrates, each subunit is encoded by a separate gene PPP3CA, PPP3CB, and PPP3CC for CnB1 and PPP3R1, PPP3R2 for CnB2 [46, 47]. The two calcineurin isoforms are widely distributed in mammalian tissues. Immunohistochemical studies showed that under normal conditions calcineurin isoforms are highly expressed in neuroinflammation-sensible neurons like corticohypothalamic pyramidal cells and cerebellar Purkinje cells, as well as in peripheral nervous system (PNS) glia like Schwann cells, but not in central nervous system (CNS) glia $[37,48,49]$.

The subcellular distribution of calcineurin is an important control point in regulating its activity. Various studies addressed the subcellular localization of calcineurin in various mammalian cells $[2,50,51]$. In neurons, calcineurin was found in the cytoplasm, endoplasmic reticulum, Golgi apparatus, nucleus, synaptic vesicles, microsomes, mitochondrion outer membrane, and plasma membrane $[2,48,49,51,52]$.

2.2. NFAT Transcription Factors. NFAT proteins are a family of transcription factors normally found in the cytoplasm in a hyperphosphorylated (inactive) state [53-55]. This family comprises five distinct gene products termed (i) NFATc, NFAT2, or NFATc1; (ii) NFATp, NFAT1, or NFATc2; (iii) NFATx, NFAT4, or NFATc3; (iii) NFAT3 or NFATc4; and (iv) osmotic response element-binding protein (OREBP), tonicity-responsive binding-protein (TonEBP), or NFAT5 $[56,57]$. In the context of this review, nomenclature of NFATc1-c4 and NFAT5 will be used.

NFATcl-c4 occur as monomers with unique amino and carboxyl termini containing transcription activation domains (TADs) and two conserved domains: (i) a regulatory domain termed NFAT homology region (NHR), which shows a lesser degree of pair-wise sequence identity but has several strongly conserved sequence motifs characteristic of the NFAT family; and (ii) the Rel homology region (RHR) in the C-terminus, where the DNA binding domain (DBD) is located $[14,56]$. The NHR encompasses calcineurin docking sites, a nuclear localization signal (NLS) responsible for calcineurin-mediated nuclear translocation, and an extended serine-rich region $[44,58-61]$. On the other hand, the DBD binds DNA and interacts with partner proteins to transactivate gene transcription. Examples of partner transcription factors include AP-1 cell life and death regulators [dimeric transcription factors composed of activating transcription factor (ATF), Fos, or Jun subunits] and important oncogenic regulators like myocyte enhancer factor-2 (MEF2) and GATA binding protein 4 (GATA4) $[60,62]$. Regions out of the regulatory and DNA binding domains like TADs demonstrate relatively little sequence conservation $[57,59]$. NFAT5 is a homodimer with a distinct domain structure. This isoform retains only the $\mathrm{RHR}$ region of homology to the $\mathrm{Ca}^{2+}$ regulated isoforms, whilst the remaining 600 amino acids are completely different. The DBD of NFATs is distantly related to the DBD of nuclear factor kappa B $(\mathrm{NF}-\kappa \mathrm{B}) / \mathrm{Rel}$ family, allowing them to be classified sometimes as members of this extended family $[63,64]$.

NFATs regulate the transcriptional induction of genes encoding for immune modulators/activators such as granulocyte-macrophage colony-stimulating factor (GM-CSF), forkhead box P3 (FOXP3), immunoglobulin kappa (Ig $\kappa)$, gamma interferon (IFN $\gamma)$, CD5, CD25, CD28, CD40, interleukin- (IL-) 2, IL-3, IL-4, IL-5, IL-13, IL-8, Th2-type cytokine IL-31, Fas ligand, macrophage inflammatory protein 1 alpha (MIP-1 $\alpha$ ), protein tyrosine kinase Syk, cyclooxygenase 2 (COX-2), and tumor necrosis factor alpha (TNF- $\alpha$ ) and its family member BlyS. NFATs may also control genes encoding signaling molecules as variate as $\mathrm{Ca}^{2+}$ regulators [inositol 1,4,5-trisphosphate $\left(\mathrm{IP}_{3}\right)$ receptor $\left(\mathrm{IP}_{3} \mathrm{R}\right)$, regulator of calcineurin 1 (RCAN1)], growth factors (VEGF, neurotrophins), myelination genes (P0 and Krox-20), glucose regulation genes (insulin, HNF1, PDX, and GLUT2), cell cycle and death regulator/activators $\left[\mathrm{p} 21^{\text {Waf1 }}, \mathrm{c}-\mathrm{Myc}\right.$, cyclin-dependent kinase 4 (CDK4), B-cell lymphoma 2 (Bcl-2), and cyclins A2, D1, and D2], oncogenes (Wnt, $\beta$-catenin), microRNAs (miR-21, miR-23, miR-24, miR-27, miR-125, miR-195, miR199, and miR-224), and surfactants (sftpa, sftpb, sftpc, and abca3) [9, 65-74]. NFAT isoforms are ubiquitously expressed and are generally regulated by $\mathrm{Ca}^{2+}$ signaling, with exception of NFAT5 [59, 75, 76]. NFAT5 regulates hypertonic stressinduced gene transcription, whereas the other NFATs act as integrators of $\mathrm{Ca}^{2+}$ driven signaling pathways in gene expression and cell differentiation programs $[57,77,78]$.

All $\mathrm{Ca}^{2+}$-regulated NFATs (NFATcl-c4) are expressed in neurons [79]. The previously assumed functional redundancy of NFAT functions was proved wrong by their wide-ranging expression profile among cell types under both physiological and pathological conditions. For example, loss of specific NFAT subtypes resulted in cardiovascular, skeletal muscle, 
cartilage, neuronal, and/or immune system defects $[54,59$, $80,81]$. In addition, Vihma and colleagues reported that NFAT subcellular localizations and transcriptional activities are isoform- and cell type-specific [37]. In that context, the strongest transcriptional activators were NFATc3 and NFATc4 in primary hippocampal neurons and NFATc1 and NFATc3 in human embryonic kidney-derived HEK293 cells.

2.3. Signaling Activation. The activation of calcineurin/NFAT signaling pathway involves three key steps: (i) NFAT protein dephosphorylation by calcineurin; (ii) nuclear translocation of NFATs; and (iii) increased affinity for DNA. Ligandreceptor interaction activates phospholipase $\mathrm{C}$ (PLC) resulting in the release of $\mathrm{IP}_{3}$, which in turn leads to the release of $\mathrm{Ca}^{2+}$ from intracellular stores through $\mathrm{IP}_{3} \mathrm{Rs}[59,82]$. Notably, $\mathrm{Ca}^{2+}$ release from the intracellular stores requires a stimulus capable of generation of second messengers that trigger $\mathrm{Ca}^{2+}$ release from intracellular stores in the endoplasmic/sarcoplasmic reticulum, via channels of $\mathrm{IP}_{3} \mathrm{R} 1-$ 3 and ryanodine receptors (RyR1-3) [59, 83-87]. Like for other $\mathrm{Ca}^{2+} / \mathrm{CaM}$-dependent enzymes, calcineurin activation requires increase in cytosolic $\mathrm{Ca}^{2+}$ levels. Such activation may result from the binding of $\mathrm{Ca}^{2+}$ to calcineurin $\mathrm{B}$ subunit or from the binding of $\mathrm{Ca}^{2+}$-activated $\mathrm{CaM}$ to calcineurin [50]. In turn, calcineurin activates NFATs by dephosphorylating multiple $\mathrm{N}$-terminal phosphoserine residues in the regulatory domain. Such dephosphorylation increases NFAT affinity for DNA [59]. The dephosphorylation results in a conformational change in the NFAT molecule that exposes the nuclear localization signal, allowing NFAT nuclear translocation to take place, presumably through nuclear pores [88]. In the nucleus NFATs become transcriptionally active by forming complexes with other factors and coactivators, providing a direct link between intracellular $\mathrm{Ca}^{2+}$ signaling and gene expression. Calcineurin also promotes nuclear retention of NFAT by masking nuclear export signals (NES) and preventing NES-dependent nuclear export [88, 89]. Moreover, calcineurin mediated NFAT activation is mainly required at resting state (resting membrane potential), where the amount of $\mathrm{Ca}^{2+}$ released from intracellular stores is not sufficient for direct NFAT activation $[75,90]$.

\subsection{Regulation and Pharmacology}

2.4.1. Endogenous Regulation. Regulators of calcineurin (RCANs) or modulatory calcineurin-interacting proteins (MCIPs; MCIP1-3) belonging to the calcipressin family of proteins play a pivotal role in regulating calcineurin activity. The RCANs are evolutionarily conserved proteins that can directly bind and inhibit calcineurin. The RCAN1 genes are found on chromosome 21. The RCAN gene encodes different isoforms of protein, namely, RCAN1, RCAN2, RCAN3, and RCAN4 where RCAN1 and RCAN4 are the main isoforms. Furthermore, it appears that RCAN1 has two RCAN1 isoforms: 1S with 197 amino acids and RCAN.1L with 252 amino acids. Previous studies have shown that an aberration in RCANs activities decreases calcineurinNFAT signaling activities. Recent studies have shown that
RCANs can show both inhibitory and facilitatory roles in activation of the calcineurin-NFAT signaling pathway. A mechanistic explanation on how RCAN proteins precisely modulate calcineurin function is still debatable. Overall RCANs have been implicated to function primarily as chaperones for calcineurin biosynthesis or recycling, requiring binding, phosphorylation, ubiquitylation, and proteasomal degradation for their stimulatory effect [50, 91, 92]. Other regulators including scaffolding proteins, CAIN/CABIN-1, and A-kinase anchoring protein 79 (AKAP79) have also been identified to interact and inhibit calcineurin function in a phosphorylation-dependent manner in mammalian cells (details given below).

2.4.2. Endogenous Inhibition. The regulation of calcineurin/ NFAT activity is achieved: (i) in the nucleus by activities of serine/threonine kinases promoting the export of nuclear NFAT; (ii) in the cytoplasm, through phosphorylation of NFAT serine (SP) repeats and N-terminal domain, which are critical for NFAT activation and nuclear import [88, 93, 94]. Various kinases were implicated in NFAT nuclear export. Examples include glycogen synthase kinase (GSK), protein kinase A (PKA), casein kinase, and also mitogen-activated protein kinases (MAPKs) like c-Jun $\mathrm{NH}_{2}$ - terminal kinases (JNKs) and cellular stress-associated p38 kinase [14,54]. Although different kinases have been implicated in regulating NFAT activity, the distinction between drivers and passengers in the cytoplasm and in the nucleus is still puzzling. Notably, it is not clearly understood whether the kinases which mediate rephosphorylation of nuclear or activated NFATs are similar to those that phosphorylate NFATs under basal state conditions $[14,54]$. Other early reports from targeted genetic and pharmacological manipulations suggest that members of the JNK family regulate both the import and export of NFATs while p38 MAPKs mediate NFAT rephosphorylation, thus NFAT nuclear export [13, 89, 95].

Calcineurin/NFAT signaling blocking agents mainly act at calcineurin and NFAT levels. They include cellular (protein inhibitors) and pharmacological inhibitors. Although numerous endogenous proteins may have potential to inhibit calcineurin or NFAT activities, only four are wellcharacterized: (i) A-kinase anchoring protein 79 (AKAP79), a scaffold protein that prevents calcineurin-substrate interactions [96, 97]; (ii) calcineurin inhibitor (CAIN) or calcineurin-binding (CABIN) proteins, which block calcineurin activity [98, 99]; (iii) calcineurin homologous protein (CHP); and (vi) modulatory calcineurin-interacting proteins (MCIP1-3), which prevent NFAT nuclear import by preventing its phosphorylation [94, 100-103].

2.4.3. Pharmacological Inhibition. Two pharmacological inhibitors of NFAT translocation, namely, cyclosporine A, FK506 (tacrolimus), and its ethyl analog ascomycin, are commonly used as immunosuppressants, particularly in organ transplantation [104-107]. These chemically distinct microbial products inhibit calcineurin activity by binding with subnanomolar affinity to cytosolic proteins called immunophilins. The resultant drug-protein composite binds tightly to calcineurin and blocks its phosphatase activity by 
preventing substrate access $[14,59]$. Cyclosporine A binds to cyclophilin and FK506 binds to FK506-binding protein (FKBP) $[88,108]$. These inhibitors indiscriminately block all downstream calcineurin signaling, including various signaling pathways collaborating with calcineurin/NFAT signaling pathway $[39,93]$. Such complete blockade of calcineurin activities may explain at least partly the serious side effects of cyclosporine A and FK506 [104, 105], particularly in pediatric patients $[106,107]$.

Recent studies in rat brain slices and cultured astrocytes revealed that cyclosporine A increases reactive oxygen species (ROS) formation and alters glucose and energy metabolism partly by Krebs cycle inhibition and anaerobic glycolysis activation [109]. These detrimental effects probably participate in cyclosporine A neurotoxicity. Additionally, inhibition of NFAT activity suppressor GSK-3 mediated by wild-type mice chronic treatment with lithium or cyclosporine A resulted in increases in nuclear translocation of NFATc3 and Fas-dependent apoptosis in brain neurons, accompanied by pronounced motor deficits [110]. In the same study, neither neuronal loss nor motor deficits were observed in Fas deficient Tet/DN-GSK-3 mice, suggesting that GSK-3 contributes to the neurological toxicity induced by cyclosporine A. Therefore, GSK-3 inhibitors may improve calcineurin inhibitor neurotoxicity. Cyclosporine A may also mediate neuronal affection by decreasing biometal availability [111-113].

Moreover, experimental evidence has shown increases in spinal NMDA receptor activity as a result of calcineurin inhibitor induced pain syndrome (CIPS) [114-116]. A wholecell patch-clamp study in spinal cord slices revealed that the effect may be mediated by the potentiation of pre- and postsynaptic NMDA receptor activity in the spinal cord [114]. In the same study, it was shown that FK506 treatment increased drastically the amplitude of excitatory postsynaptic currents mediated by NMDA receptor in dorsal horn neurons. Inhibitors of the serine/threonine protein kinase casein kinase II (CK2) involved in the upregulation of synaptic NMDAR activity in neurons abrogated pain hypersensitivity caused by FK506 [117, 118]. Nonetheless, cyclosporine A also mediated neuropathic pain independently of NMDA receptor $[108,118]$, suggesting that the processes mediating CIPS are complex and warrant further studies.

Interestingly, inhibitors that do not block calcineurin enzymatic activity per se, but rather interfere with enzyme targeting of one or more of its substrates, have recently been developed and used. For instance, the inhibitors of NFATcalcineurin association (INCA) compounds may interfere selectively with calcineurin/NFAT interaction without preventing dephosphorylation of other calcineurin substrates $[119,120]$. Substrate-selective enzyme inhibition represents an important progress over cyclosporine A or FK506mediated complete blockade of calcineurin/NFAT signaling. This development is expected to lead to the development of safer classes of calcineurin/NFAT inhibitors. Certainly, the beneficial actions of cyclosporin A and FK506 are counterbalanced by serious toxicities attributed partly to their interference with calcineurin signaling in other cells and tissues. Although INCA have nonspecific cytotoxic effects, they are generally considered to be less toxic than treatment with cyclosporine A or FK506.

\section{Nervous System Development}

Calcineurin/NFAT signaling pathway is multifunctional. In the PNS, calcineurin/NFAT signaling was reported to have critical roles in the survival, proliferation, and differentiation of both neural and glial precursor cells [22], highlighting its potential role in tissue regeneration. Similar lines of evidence suggest that calcineurin/NFAT plays critical roles in the regulation of the CNS development, including corticogenesis and synaptogenesis.

3.1. Corticogenesis. Evidence supporting the involvement of the calcineurin/NFAT4 signaling pathway in corticogenesis includes a study in developing mouse cerebellar granule neurons that reported a pivotal role in controlling the temporal regulation of nuclear factor 1 occupancy. This serves as a key link between membrane potential and dendritic maturation, by a voltage-sensitive developmental switch [121]. In addition, the multifunctional HMG-box transcription factor Tox, a novel regulator of mammalian corticogenesis, is regulated by calcineurin/NFAT signaling [19]. Genetic and biochemical analyses in the developing embryo revealed that fibroblast growth factor- (FGF-) mediated calcineurin signaling may trigger neural induction by increasing Smad1/5 transcription via silencing of bone morphogenetic protein (BMP) signaling [122]. Furthermore, store-operated $\mathrm{Ca}^{2+}$ entry (SOCE) activation regulates gene transcription in the developing nervous system and mediates neural progenitor cell proliferation through calcineurin/NFAT signaling [123-125].

The role of the calcineurin/NFAT signaling in corticogenesis is probably mediated by NFATc3, the predominant NFAT isoform in neural progenitor cell cultures, which is also a potent inducer of neural progenitor cell differentiation into neurons and astrocytes $[22,126]$. Interestingly, activitydependent NFATc3 accumulation in the nucleus was reported in pericytes from cortical parenchymal microvessels [127], and differential expressions of NFATc3 and NFATc4 were reported in developing rat brain and traumatic brain injury models, where NFATc4 was primarily expressed by neurons and NFATc3 by astrocytes [125, 128]. These observations suggest that different NFATs are recruited at the same time in resident cells of damaged and growing nervous tissue, indicating that characterizing the effects of such NFAT changes in specific cell types may provide new therapeutic targets for neurodevelopmental disorders.

3.2. Synaptogenesis. The complex interactions between inhibitory gamma-aminobutyric acid (GABA) and excitatory NMDA receptor activities are required during synaptogenesis. Furthermore, this interaction plays an important role in the induction of immediate early genes necessary for effective changes in synaptic plasticity and long-term memory formation through calcineurin-dependent transcription of the key brain-derived neurotrophic factor (BDNF) $[20,23,129,130]$. Of particular interest for neurodevelopmental treatments is a recently reported novel 
synthetic neurotrophic (BDNF and neurotrophin-like) compound that is able to induce neurite growth and confer neuroprotection [21]. In addition, the neurotrophin nerve growth factor (NGF) is known to upregulate the key regulator of plasminogen activation system and synaptogenic protein plasminogen activator inhibitor 1 (PAI-1) in primary mouse hippocampal neurons via calcineurin/NFAT signaling [131]. Protein kinase C (PKC)/calcineurin signaling-mediated dephosphorylation of axon growth regulatory molecule growth-associated protein 43 (GAP43) at developing GABAergic synapses resulted in pathological processing mimicking neonatal hypoxia, including misfolding of gephyrin, a protein critical for the organization of GABA receptors [132]. Calcineurin signaling also mediates the GABAergic synaptic modulation induced by transient receptor potential vanilloid type 1 (TrpV1), a ligand-gated channel abundantly expressed in developing primary sensory neurons $[133,134]$. Certainly, these observations suggest that calcineurin signaling is involved in the development of GABAergic synaptic functions in the CNS.

Moreover, GABA promoted the shrinkage and elimination of synapses by suppressing local dendritic $\mathrm{Ca}^{2+}$ signaling in rat hippocampal CA1 pyramidal neurons via a mechanism depending on calcineurin and on actin-binding protein cofilin [135]. Similarly, more recent studies also suggested that calcineurin is a major signaling molecule in the selection of synapses, a critical mechanism in the reorganization of the developing and adult CNS mediated by the major inhibitory neurotransmitter GABA [132, 135, 136].

3.3. Endosome Trafficking. It is now widely accepted that calcineurin signaling is a major player in the control of the trafficking and signaling of endosomes performing the retrograde signaling, an event critical for the development, but also for the nervous system function $[2,137,138]$. Calabrese and colleagues reported calcineurin signaling modulation as a key event in the differential regulation of dynamins, major players of synaptic vesicle recycling in nerve terminals of developing neurons [137]. Notably, these authors observed that tetrodotoxin- (TTX-) mediated chronic suppression of neuronal activity results in the suppression of dynamin 1 clustering at nerve terminals and in an increase of clustering of dynamin 3, partly mediated by calcineurin signaling silencing. In addition, NGF-mediated calcineurin/NFAT signaling is critical for the control of endosome trafficking in neurons [77, 131, 138]. Such NGF/calcineurin/NFAT control of the trafficking of endosomes is under the control of the effector protein coronin-1 and regulatory events such as the phosphorylation of cAMP responsive element binding protein (CREB), which are also mediated by NGF receptor tropomyosin receptor kinase type 1 (TrkA) [138].

Notably, as other tyrosine kinase receptors, the receptors of neurotrophins may also activate NFATs via inhibition of the promoter of NFAT nuclear export GSK-3 $\beta$, independent of $\mathrm{Ca}^{2+}$ and calcineurin signaling. For instance, a study assessing the physiological roles of estrogen-related receptor gamma (ERR $\gamma$ ), an orphan nuclear receptor highly expressed in the nervous system during embryogenesis and over lifespan, revealed its involvement in the regulation of dopaminergic neuronal phenotype. Such effect was mediated by GSK$3 \beta$-NFAT interactions, independently of $\mathrm{Ca}^{2+} /$ calcineurin signaling [139]. Similar, NGF facilitated NFAT-mediated gene expression induced by mild depolarization in dorsal root ganglion sensory neurons without changes in PLC activity-dependent events, including $\mathrm{Ca}^{2+} /$ calcineurin signaling. Instead, NGF effects were induced by phosphoinositide 3-kinase (PI3K)/Akt signaling triggered by TrkA receptor activation, which abrogated GSK-3 $\beta$ activity [77].

Furthermore, calcineurin is universally involved in vesicle endocytosis [12], and alterations in its endocytic activity may participate in the pathogenic processes of various psychiatric diseases. For instance, alterations in presynaptic functions of the $\gamma$ isoform of the calcineurin catalytic subunit, such as synaptic vesicle cycling, have been suggested to contribute to schizophrenia, where variations in calcineurin A $\gamma$ gene PPP3CC are common in neurons [140]. Deregulation of intracellular $\mathrm{Ca}^{2+}$ also associates with the disruption of fast axonal transport (FAT) in the pathogenesis of Alzheimer's disease (AD) [141-144].

\section{Nervous System Function}

Calcineurin/NFAT has critical roles in neuronal and glial cell activity and survival, as well as resulting events, fundamental for nervous system function like neurotransmission and synaptic plasticity, and myelination as summarized in Figure 1.

\subsection{Synaptic Plasticity and Neurotransmission}

4.1.1. Synaptic Connectivity and Plasticity. Calcineurin/NFAT signaling and other pathways activated by T-type $\mathrm{Ca}^{2+}$ channel activation play critical roles in the shaping of synaptic connectivity of thalamocortical and nucleus reticularis thalami GABAergic neurons mediated by slow wave sleep [145], a process pivotal for the consolidation of recently acquired memories and for the restoration of synaptic homeostasis. This mechanism may be evolutionary conserved [54, 146, 147]. PLC/calcineurin signaling has been reported to regulate the trafficking of GABA A receptor in layer 3 pyramidal cells of murine barrel cortex [136]. Furthermore, the inhibition of group I metabotropic glutamate receptors (mGluRs), IP3Rs, or calcineurin in CAl neurons resulted in the blockade of the heterosynaptic shrinkage $[85,87]$ that drives circuit remodeling during activity-dependent refinement of the developing nervous system and during experience-dependent plasticity in the hippocampus. This inhibition has been reported to negatively affect long-term potentiation (LTP) [87].

Experimental evidence also suggests that calcineurin is a regulator of synaptic plasticity. For instance, axon initial segment rapid shortening was partly mediated by calcineurin-dependent mechanisms, including phosphorylation of voltage-gated $\mathrm{Na}^{+}$channels, in dentate granule cells [148]. Rapid modulation of the axon initial segment, the site of action potential initiation, is the major plasticity mechanisms used by neurons to control their excitability time from 


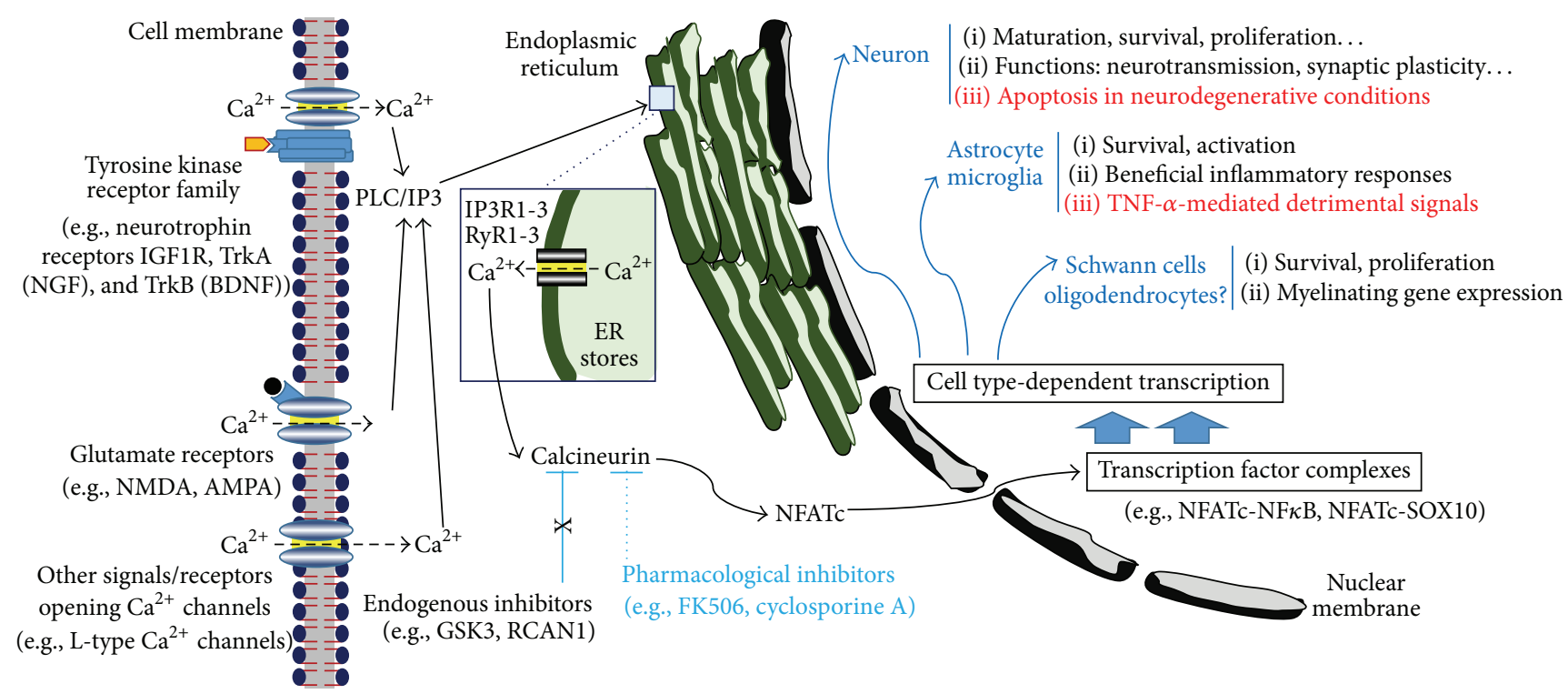

FIGURE 1: Calcineurin/NFAT signaling pathway. Calcineurin/nuclear factor of activated T-lymphocytes (NFAT) signaling activation in the nervous system is mainly induced by neurotrophins via their tyrosine kinase receptors, glutamate receptors, and nonligand-dependent receptors, such as voltage-gated $\mathrm{Ca}^{2+}$ channels in hippocampal neurons. The genes transcribed and the effects of these signaling pathways are cell-type dependent. Abbreviations: AMPA, $\alpha$-amino-3-hydroxy-5-methyl-4-isoxazolepropionic acid; BDNF, brain-derived neurotrophic factor; GSK3, glycogen synthase kinase 3; IGF1R, insulin-like growth factor 1 receptor; $\mathrm{IP}_{3} \mathrm{R}$, inositol 1,4,5-trisphosphate receptor; NF- $\kappa \mathrm{B}$, nuclear factor kappa B; NFATc, $\mathrm{Ca}^{2+}$-regulated NFATs; NGF, neurotrophin nerve growth factor; NMDA, N-methyl-D-aspartic acid; RCAN1, regulator of calcineurin 1; RyR; ryanodine receptor; TrkA, tropomyosin receptor kinase type 1; TrkB, tropomyosin receptor kinase type 2.

seconds to days. In another study, decreases in resting $\mathrm{Ca}^{2+}$ levels associated with prolonged blockade of synaptic activity resulted in the synthesis of retinoic acid, which triggered the related homeostatic synaptic plasticity, via a calcineurindependent mechanism in neurons [149]. Moreover, spinogenesis enhancement in hippocampal neurons by the steroid hormones dihydrotestosterone and testosterone was blocked by individual antagonism of PKC, PKA, calcineurin, LIM kinase (LIMK), or the MAPKs Erk and p38 [150]. Similar, estradiol-mediated rapid modulation of synaptic plasticity, an essential process for synaptic regulation, was abrogated by individual targeting of PI3K, PKC, PKA, calcineurin, CaM kinase II (CaMKII), LIMK, Erk, or p38, in hippocampal neurons [151].

4.1.2. Learning and Neurotransmission. Evidence of calcineurin/NFAT involvement in learning and memory processes was provided by experimental models of neurodegenerative disorders. A study in PS1-M146V knock-in FAD mice showed that decreased calcineurin activity is a common phenomenon in aging-related memory decline and may account for memory defects in AD, together with mutations in the gene encoding for GSK-3 $\beta$ substrate presenilin 1 (PS1) [152], which are critical for amyloid- $\beta$ (A $\beta)$ generation. In a study using a spinocerebellar ataxia type 3 (SCA3) transgenic mouse model, typical impairments of motor learning and cerebellar motor coordination resulted from altered long-term depression (LTD) of glutamatergic transmission in parallel fiber-Purkinje neurons [153]. Such alteration resulted mainly from transcriptional downregulation of PLC $\beta 4$, IP3R1, and calcineurin B, suggesting that
$\mathrm{PLC} / \mathrm{IP}_{3}$ - Rs/calcineurin signaling is required for cerebellar LTD induction, thus motor learning and coordination.

Calcineurin/NFAT signaling is also involved in neuronal excitability and neurotransmission. Under physiological conditions, AKAP79/150-mediated calcineurin/NFAT signaling may prevent neuronal hyperexcitability in hippocampal neurons by increasing the transcriptional expression of key regulators of neuronal excitability like $\mathrm{M}$-type $\mathrm{K}^{+}$channels [154]. PKC/calcineurin/NFAT signaling contributes to the maintenance of cyclic nucleotide-gated (HCN) channels in the hyperpolarized status critical for their mediation of neuronal excitability decrease in the distal dendrites of hippocampal CA1 pyramidal neurons [155], and membranederived bioactive phospholipid lysophosphatidic acid type 1 (LPA1) triggers RhoA/Rho kinase (ROCK)/calcineurin signaling to induce the internalization of the GABAA $\gamma 2$ subunit at inhibitory synapses [156].

4.2. Calcineurin-PKA Interactions. The interplay between calcineurin and PKA signaling plays a critical role in the negative-feedback mechanism driving homeostatic synaptic plasticity [157], that is, accounting for the compensation of excessive inhibition or excitation of neuronal activity. Although calcineurin/NFAT signaling mainly regulates axon terminal remodeling, while PKA/CREB signaling controls synaptic vesicle accumulation [158], many lines of evidence suggest mutual inhibitory interactions between the activities of these signaling pathways. Examples include the activity of these signaling molecules when anchored to AKAP79/150. PKA kinase activity triggered by anchoring to AKAP79/150 
resulted in the enhancement of $\mathrm{Ca}^{2+}$-dependent inactivation of L-type $\mathrm{Ca}^{2+}$ channels, while the activation of the phosphatase activity of AKAP79/150-anchored calcineurin reversed such PKA action, reducing $\mathrm{Ca}^{2+}$-dependent inactivation $[96,159]$. The basal activity of AKAP79/150-anchored PKA maintained L-type $\mathrm{Ca}^{2+}$ channel-calcineurin/NFAT signaling functional coupling by preserving the phosphorylation of these channels, contrary to anchored calcineurin [159, 160]. Interestingly, such AKAP79/150 activity mediated the modulation of roundabout axonal guidance receptors Robo2/ 3 and ligands Slit2/3 in brain regions involved in reward, learning, and memory processes like islands of Calleja and the hippocampus [97].

Furthermore, PKA can induce NFAT nuclear export $[14,54]$. PKA activation by forskolin-stimulated cAMP increased the stability and half-life of RCAN1 protein, enhancing its inhibitory effects on calcineurin [161]. In a recent study in pilocarpine-induced status epilepticus, a murine model of temporal lobe epilepsy (TLE), the nuclear translocation of CREB-regulated transcription coactivator 1 (CRTC1), which is a key regulator of CREB activity, was regulated by calcineurin activity in hippocampal neurons [24].

Opposite effects of calcineurin and PKA were also reported as key events in (i) the dynamic fission-fusion events that determine the shape and function of mitochondria [162, 163], thus cell survival; (ii) neuronal output stabilization induced by tonic dopamine via type 1 dopaminergic receptors [164]; and (iii) the phosphorylation/dephosphorylation of serine 897 in the NR1 subunit of the NMDA receptor (pNR1), whose increases in phosphorylation were reported in acute morphine withdrawal [30].

4.3. Myelination. Available data suggest that calcineurin/ NFAT pathway participates in signaling cascades pivotal for Schwann cell myelination. Early studies reported that (i) murine Schwann cells express all $\mathrm{Ca}^{2+}$-dependent NFAT isoforms; (ii) the promoter and upstream enhancer elements of the myelinating factor Krox-20 contain NFAT binding sites; and (iii) NFATs recruited by $\mathrm{Ca}^{2+}$-dependent signaling can make transcriptionally active complexes with Krox-20 [9, 93, 165]. Reporter assays showed that Krox-20 is NFAT target gene and that calcineurin is upregulated in Schwann cells expressing Krox-20 $[8,166]$. Moreover, we reported using rat Schwann cell cultures and an in vitro model of myelination that promyelinating actions of calcineurin/NFAT signaling, including increases in the expression of the myelinating genes Krox-20, Periaxin, and PO, require cAMP elevation [9]. Notably, in the absence of cAMP elevation, increase in cytosolic $\mathrm{Ca}^{2+}$ failed to induce Krox-20 expression. Furthermore, cyclosporine A and FK506 abrogated Krox-20 expression. Comparable observations were reported more recently by other authors $[165,167]$.

Experimental evidence also suggests that the activation of calcineurin/NFAT required for Schwann cell myelination occurs partly through neuregulin 1 (NRG1) stimulation $[8$, 168-170]. A study in mice lacking calcineurin B in cells of the neural crest lineage showed that calcineurin/NFAT signaling is required for NRG1-mediated Schwann cell myelination [170]. In this model NFAT activation failed, Krox-20 levels in Schwann cell were decreased, and radial sorting and myelination were markedly delayed $[8,170]$. NRG1 addition to neuron-Schwann cell cocultures promoted the activation of NFAT isoforms and cooperative transcriptional activities of NFATc4 and SOX10 required for Krox-20 upregulation $[168,169]$. In addition, NRG1/calcineurin/NFAT signaling upregulates myelinating genes in Schwann cells $[8,168,171]$.

Unexpectedly, FK506 stimulated Schwann cell proliferation and promoted the survival of oligodendrocyte in murine models of traumatic spinal cord injury [172-174], suggesting that this signaling pathway is involved in the maintenance, thus activity, of myelinating cells in both peripheral and central nervous systems. Moreover, NFAT1 hyperactivation decreased experimental autoimmune encephalomyelitis induced by myelin oligodendrocyte glycoprotein (MOG), a key regulator of CNS myelination $[175,176]$.

\section{Controversial Roles in Nervous System Diseases}

\subsection{Neurodegenerative Diseases}

5.1.1. Pathogenic Roles. Increased calcineurin activity was reported in both aging and $\mathrm{AD}$ models $[27,177,178]$. For instance, calcineurin/NFAT signaling may mediate the aberrant activity of deregulated plasma membrane $\mathrm{Ca}^{2+}$ pumps (PMCAs), a suggested link between brain aging and the onset of neurodegenerative diseases $[27,179,180]$. The strongest AD genetic risk factor, the apoE4 allele, encodes for apolipoprotein E4 that has poor inhibitory abilities on calcineurin activity, unlike the neuroprotective apolipoproteins E2 and E3 [181-183]. Apolipoprotein E4 also drives CNS functional alterations associated with normal aging such as disturbed sleep [28, 29].

Overactivated calcineurin/NFAT signaling may contribute to synaptic plasticity affection in pathological conditions. Notably, in a postmortem study in human hippocampi, high nuclear levels of NFATs observed at the early stage of AD increased with cognitive decline severity [177]. Additionally, short exposure to $A \beta$ oligomers resulted in calcineurin activation with transient changes in postsynaptic proteins and morphological in spines, while longer exposure resulted in NFAT activation and marked spine loss in primary cortical neurons of wild-type mice [184]. A $\beta$-treatment of murine hippocampal neurons also resulted in $\mathrm{Ca}^{2+}$ signalingdependent defects in BDNF transport first in dendrites and then in axons [40]. Studies in mouse and rat models of severe childhood epilepsy revealed that calcineurin/NFAT signaling mediates seizure-induced dendrite growth suppression in pyramidal neurons and thus the resulting learning and memory impairment associated with this intractable condition [185].

NFAT signaling alterations in neurodegenerative diseases are selective. A report by Abdul and colleagues strongly suggested that such selective alteration may play a key role in $A \beta$ induced neurodegeneration [186]. These authors observed 
increases in calcineurin A activity and more marked shifts of NFATc2 and NFATc4 to nuclear compartments in human hippocampus with increased dementia severity, while even in rapid-autopsy postmortem human brain tissue NFATc1 was unchanged. NFATc2 was more active in AD patients with mild cognitive impairment, contrary to NFATc4 whose expression was mostly associated with severe dementia. Still in the same study, changes in calcineurin/NFAT4 were directly correlated to soluble $A \beta$ levels in postmortem hippocampus, while oligomeric $A \beta$ strongly stimulated NFAT activation in primary rat astrocyte cultures. In another study, NFATc4 levels were significantly increased in brains of APP/PS1 transgenic mice (AD model) and NFATc4 overexpression increased $\mathrm{A} \beta$ production in human myeloid leukemia SAS-1 cells [36], suggesting a role for NFATc4 in amyloidogenesis. Mechanisms proposed for NFAT-mediated amyloidogenesis in human and murine astrocytes include increases in the expression of the gene encoding for TMP21, a p24 cargo protein involved in $\mathrm{A} \beta$ and $\mathrm{A} \beta$ precursor protein (APP) trafficking [187-190].

5.1.2. Beneficial Effects. The role of calcineurin in aberrant $\alpha$ synuclein-mediated midbrain dopaminergic neuron toxicity, a hallmark of Parkinson's disease (PD), is controversial. In a study addressing the underlying intracellular mechanisms driving $\alpha$-synuclein-mediated neurodegeneration, transgenic expression of PD $\alpha$-synuclein A53T missense mutation promoted calcineurin/NFAT signaling, suggesting that this signaling pathway may contribute to the neurotoxic effects of aberrant $\alpha$-synuclein [191]. Surprisingly, in a study using cells from various models (ranging from yeast to neurons), although aberrant $\alpha$-synuclein also seemed to induce cellular toxicity via overactivation of $\mathrm{Ca}^{2+}$-dependent signaling pathways, calcineurin inhibition with FK506 also resulted in toxicity [192], suggesting that calcineurin may mediate both beneficial and toxic effects under stimulation by aberrant $\alpha$-synuclein. Characterizing the precise downstream targets mediating calcineurin beneficial or toxic effects may provide more insights of the novel therapeutic targets for synucleinopathies.

Calcineurin also mediates some beneficial and toxic effects of AMPA and NMDA receptors, which are postsynaptic site-located glutamate-gated ion channels critical for synaptic plasticity. Calcineurin translocation to synapses and increases in its activity mediated by NMDA receptor trafficking were reported as critical components of mechanisms driving rapid compression-induced dendritic spine plasticity in cortical pyramidal neurons, that is, the rapid trimming of dendritic spines occurring about 12 hours after mechanical compression [38]. A study using soluble $\mathrm{A} \beta$ treated in cultured rat hippocampal neurons and cultured hippocampal neurons from APPSwe AD-transgenic mice suggested that calcineurin signaling mediates AD-like synaptic dysfunction induced by tau protein partly via AMPA receptor downregulation [193]. In that study, soluble $A \beta$ oligomerinduced deficits in AMPA receptor trafficking were mediated by tau phosphorylation and mislocalization to dendritic spines. FK506 abrogated all these alterations. Concomitant tau hyperphosphorylation and calcineurin overactivation were also reported in mouse models of Huntington's disease [41]. On the other hand, IL-6/Janus kinase (JAK) signaling induced neuroprotective anti-NMDA activities in cultured cerebellar granule neurons via calcineurin-dependent inhibition of activities of NMDA receptor subunits NR2B and NR2C and concomitant inhibitions of NMDA-induced Ltype voltage-gated $\mathrm{Ca}^{2+}$ channel activity and intracellular $\mathrm{Ca}^{2+}$ store release [194].

Moreover, in AD pathogenesis, insulin-like growth factor 1 (IGF-1) that acts as a regulator of tau phosphorylation is silenced in activated astrocytes by $A \beta /$ calcineurin-induced release of IGF-1-binding protein 3 (IGFBP-3); but intriguingly, $\mathrm{A} \beta$ directly induces increases in tau phosphorylation, and resulting neuronal death, via a mechanism involving the silencing of NFAT export kinase GSK-3 $\beta$ [195], suggesting opposite roles for calcineurin in $\mathrm{AD}$ pathogenesis. IGF-1 also protected motor neurons in SOD1 transgenic mice, a widely used model of amyotrophic lateral sclerosis, via a calcineurin-dependent mechanism [196]. Although it is now widely accepted that therapeutic benefits of IGF1 treatment in neurodegenerative conditions may emerge partly from calcineurin-dependent inhibition of glial inflammatory reaction mediated by preventing TNF- $\alpha$-induced nuclear translocation of NF- $\kappa$ B [197-199], it is also clear that the expression of TNF- $\alpha$, resulting in detrimental neuroinflammation and functional alterations in neurons, is mediated by astrocytic and microglial calcineurin/NFAT signaling [200-202]. Studies in transgenic mice and in vitro models of neuroinflammatory diseases provided mechanistic insights into the context of these opposite roles. These studies showed that TNF- $\alpha$ activate calcineurin/NFAT/NF$\kappa \mathrm{B}$ canonical inflammatory pathway in quiescent astrocytes, while in activated astrocytes, IGF-1 released locally recruited calcineurin signaling to inhibit NF- $\kappa$ B-NFAT transcriptional activity through activation of the purinergic receptor P2Y6 $[203,204]$, suggesting that the activation status of the cell is an important determinant of calcineurin/NFAT activity, that is, downstream targets.

5.1.3. Pharmacological Inhibition and Endogenous Regulation. The pharmacological inhibition of calcineurin/NFAT signaling improved animal condition in a number of studies in neurodegenerative diseases and models. Examples include $\mathrm{AD}$ mouse models where pharmacological inhibition of this signaling pathway decreased $A \beta$ plaques, reduced glial activation, alleviated both $\mathrm{A} \beta$ synaptotoxicity and neurotoxicity, and improved synaptic function [25, 205-207], suggesting a therapeutic potential for calcineurin inhibitors in $\mathrm{AD}$. Reports by Kim and colleagues from studies performed in presenilin 1-mutant model of AD provided some mechanistic insights into the cognitive decline improvement resulting from reducing calcineurin activation in affected brains $[25,208]$. These authors observed that the inhibition of abnormally increased calcineurin activity characteristic of the disease resulted in the stabilization of the phosphorylation of GluAl, a subunit of $\mathrm{Ca}^{2+}$-permeable AMPA receptors, and promoted synaptic trafficking of $\mathrm{Ca}^{2+}$-permeable AMPA 
receptors, as well as the resulting improvement in animal cognition [25]. Such improvement resulted at least partly from the restoration of $\mathrm{Ca}^{2+}$-permeable AMPA receptor-mediated hippocampal LTP [208]. Decrease in calcineurin complexes with transmembrane AMPA receptor regulatory proteins (TARPs) like $\gamma-8$, which can stop the trafficking of both AMPA and to a lesser extent NMDA receptors [209-211], may also participate in this process. Furthermore, biometal mediated neurite elongation and neuritogenesis in neuron cultures via calcineurin silencing [111] and calcineurin/NFAT signaling induced a reduction in NGF expression and neurite outgrowth in rat neonatal ventricular cardiomyocytes and cultured sympathetic neurons [212, 213].

Not surprisingly considering the aforementioned observations in studies assessing the roles of calcineurin in neurodegenerative disorders (Section 5.1.2), endogenous regulators like plasma membrane calcium ATPase (PMCA) and RCAN1 mediate opposite effects in inflammatory processes. RCAN1 overexpression was reported to be pivotal in the prevention of sepsis and LPS-induced lethality [214] and in the protection against brain ischemia/reperfusion injury in murine models [215]. However, interactions of PMCA and vascular endothelial growth factor (VEGF), which dampened calcineurin/NFAT signaling, also induced the overexpression of both the counter-inflammatory factor RCAN1.4 and the proinflammatory factor COX-2 in activated murine endothelia [214, 216, 217]. Additionally, RCAN1 overexpression increased the susceptibility to oxidative stress in primary neurons [218] and exacerbated $\mathrm{Ca}^{2+}$ overloading-induced neuronal apoptosis [219], suggesting that the overexpression of calcineurin regulator RCAN1 may link $\mathrm{Ca}^{2+}$ overloading and oxidative stress in neurodegenerative disorders (Figure 1). Such detrimental effects of RCAN1 were mediated by RCAN1.4, and not by the other isoforms detected in human brain RCAN1.1 [91, 219], probably via PI3K/Akt/mTOR signaling [220, 221]. Such mechanistic insight was provided by a system study based on combinations of single-cell experimentation and in silico simulations where RCAN1 effect on inflammation mediated by calcineurin/NFAT appeared to change according to cellular levels, from inhibitory activity at low levels to facilitative activity at high levels [221]. Notably, in that study RCAN1 facilitative activity was switched on by nuclear export of GSK- $3 \beta$, indicating that targeting the factors involved in this inhibitory mechanism of GSK-3 $\beta$ mediated NFAT nuclear export may have a therapeutic potential in neurodegenerative diseases.

Considering that RCAN1 overexpression is a hallmark of Down syndrome $[219,222]$, it can be hypothesized that this event also contributes to the pathogenesis of $\mathrm{AD}$ like neuropathology typically observed in Down syndrome patients after their middle age [223, 224]. In addition, the activity of pituitary adenylate cyclase-activating peptide (PACAP), a neurotrophic peptide involved in nervous system development, learning, and memory, was significantly disturbed by changes in RCAN1 expression [225]. RCAN1 overexpression impaired neurotrophic support of sympathetic neurons by inhibiting TrkA endocytosis, resulting in NGF signaling silencing and associated neurodevelopmental deficits [92]. Furthermore, overexpression of RCAN1 or dualspecificity tyrosine-(Y)-phosphorylation regulated kinase $1 \mathrm{~A}$ (DYRK1A), another Down syndrome-associated protein, negatively regulated NFAT-dependent transcriptional activity and decreased NGF-mediated upregulation of PAI-1 levels [131], a key synaptogenic mechanism. Intriguingly, deficiency of RCAN1.1, but not RCAN1.4, affected radial migration of rat cortical neurons and caused periventricular heterotopia [226], suggesting that this RCAN1.1 isoform may mediate positive RCAN1 effects in developing cortex. Future studies using selective activations and inhibitions of RCAN1 isoforms may reveal the mechanisms accounting for isoform-specific effects in the developing cortex.

\subsection{Neurodegenerative Conditions and Other Nervous System Diseases}

5.2.1. Neurodegenerative Conditions. Alterations in the autophagy of mitochondria, the process that normally triggers damaged organelle elimination, are common in neurodegenerative diseases and conditions [227-230]. In a study using axotomized precerebellar neurons, a model of focal cerebellar lesion-induced remote degeneration, rapamycinmediated autophagy, resulted in an aberrant mitochondrial fission partly caused by increased calcineurin activity [227]. The activity of a calcineurin docking motif present in the mitochondrial fission mechanoenzyme dynamin-related protein 1 (Drp1) contributed to mitochondrial fragmentation and ischemic neuronal injury in neuronal and nonneuronal cells [163]. Additionally, calcineurin inhibitors mitigated mitochondrial fragmentation in ferric ammonium citrateexposed HT-22 hippocampal neurons, a model of iron overload and neurodegeneration [231].

Further evidence for calcineurin involvement in ischemic injury includes reports suggesting that abnormal increases in the activity of this phosphatase, mediated by disturbances in axonal $\mathrm{Ca}^{2+}$ homeostasis, may play a key role in secondary damage of neurons and capillary vessels observed during acute phase of diffuse axonal injury [173, 232]. Calcineurin signaling also mediated the activation of the cytoskeletal actin severing protein cofilin and the resulting neuronal death in oxygen-glucose deprivation/reperfusion and chemical induced oxidative stress, to in vitro models of ischemia [34]. Moreover, cyclosporine A prevented the apoptosis of astrocytes exposed to simulated ischemia in vitro via a calcineurin and Erk1/2-dependent mechanism [233] and through the inhibition of cytosolic phospholipase A2(PLA2-) mediated release of arachidonic acid [234].

Selective calcineurin signaling in neurons and astrocytes is a key player in neurodegenerative conditions. An early study addressing neuronal apoptosis induced by the abused psychostimulant methamphetamine revealed pivotal roles for calcineurin activation and resulting Fas ligand upregulation mediated by nuclear translocations of NFATc3 and NFATc4 in rats [235]. The potent hepatotoxin microcystin-LR (MCLR) mediated an upregulation of calcineurin and NFATc3 levels in rat hippocampal neurons that resulted in marked increases in apoptotic and necrotic cell death [32]. MCLR effect 
was prevented by FK506 treatment. In addition, NFATc4 mediated light-induced retinal ganglion cell apoptosis by upregulating Fas ligand (FasL) expression on retinal neurons [236], and the overactivation of calcineurin/NFATc3 signaling induced the typical neuronal toxicity and functional alterations observed in murine developing hippocampal neurons following the inhalation of anesthetic isoflurane, including cognitive impairment [237]. A recent study in this model of postoperative cognitive dysfunction revealed that abnormal calcineurin/NFAT signaling associated with isoflurane exposure may mediate its detrimental effects by promoting the degradation of the survival molecule signal transducer and activator of transcription 3 (STAT3) [238]. Moreover, calcineurin/NFATc3 signaling in activated astrocytes played a key role in the induction of alterations in synaptic remodeling and homeostasis observed in the hippocampus in controlled cortical impact injury in rats $[39,128,239]$. As expected, calcineurin inhibition restored synaptic function and plasticity in the latter murine model of traumatic brain injury and in murine models of traumatic spinal cord injury [172174] partly by abrogating astrocyte activation and reactive gliosis, which are pivotal events in neuroinflammationmediated neuronal loss. Notably, calcineurin/NFAT signaling is critical for astrocyte activation [205, 240]. In another study in ischemic striatum and cortex and in cultured astrocytes where FK506 also induced neuroprotective effects, the calcineurin inhibitor prevented astrocyte apoptosis mediated by glutamate signaling [241].

Altogether, these observations suggest a role for calcineurin/NFAT signaling in astrocyte and neuronal losses observed in nervous system injury. Unexpectedly, sublethal ischemia increased neuronal resistance to excitotoxicity via calcineurin-dependent mechanisms including cyclin E1 protein increased expression and declustering of the delayed rectifying $\mathrm{K}^{+}$channel $\mathrm{Kv} 2.1$ at highly phosphorylated somatodendritic clusters [242]. In addition, preconditioning of neurons with biometal ions $\left(\mathrm{Cu}^{2+}, \mathrm{Zn}^{2+}\right)$ protected these cells against NMDA receptor-induced excitotoxicity, through metal chaperone PBT2-induced calpain cleavage of calcineurin [111, 112]. Thus, calcineurin/NFAT pathway participates in the interplay between proinflammatory and counterinflammatory signals in the nervous system, further suggesting that unraveling the downstream targets accounting for beneficial and neurotoxic effects of this signaling pathway may have a therapeutic potential in neurodegenerative conditions.

5.2.2. Psychotic Disorders. Early genetic studies showed that polymorphisms of the genes coding for either the catalytic or regulatory subunit of calcineurin isoenzymes are strongly associated with the risk for developing schizophrenia and other psychotic disorders whose pathological features include disturbances in $\mathrm{Ca}^{2+}$ signaling [46, 243-246]. A more recent genome-wide weighted coexpression network analysis on neural progenitors and neurons from individuals with Timothy syndrome, an autism spectrum disorder resulting from mutations in the gene encoding L-type CaV1.2 $\mathrm{Ca}^{2+}$ channels, suggested that the disease may be caused by disturbances in transcriptional activities of $\mathrm{Ca}^{2+}$-dependent signaling molecules like FOX proteins, MEF2, CREB, and NFATs [247].

Furthermore, GABA A receptor activation promoted a decrease in anxiety indicators and hippocampal neurogenesis via the calcineurin/NFAT4 signaling in mice, suggesting that pharmacological targeting of this signaling pathway may improve emotional disorders [248]. Similar evidence from pharmacological and postmortem studies suggests that treatment with antipsychotics aimed at ameliorating some of the symptoms of the CNS disorders leads to alterations of the calcineurin expression pattern in the human brain [249253]. Decreased calcineurin levels in the nucleus accumbens were reported in opioid withdrawal, a dysphoric state associated with complications in patient pain and increased risk of drug abuse and addiction [30], suggesting a role for calcineurin in long-lasting behaviors associated with reward. Furthermore, in a patch-clamp electrophysiology and fast-scan cyclic voltammetry study in mouse brain slices, the endogenous modulatory peptide neurotensin induced a long-term prevention of pathogenic increases in presynaptic dopamine release, characteristic of schizophrenia and other severe mesencephalic pathologies, by increasing inhibitory D2 dopamine autoreceptor function via a calcineurindependent mechanism [35].

5.2.3. Epilepsy. Many lines of evidence also support calcineurin involvement in nervous system diseases. Notably, various reports have suggested that calcineurin is likely to mediate physiological and pathological activities of GABA receptors. For instance, complex interactions between PKC and calcineurin may play a key role in GABA B autoreceptormediated functional regulation of nicotinic acetylcholine receptors (nAChRs), whose activation triggers the release of neurotransmitters from presynaptic nerve terminals, in mouse striatal GABAergic nerve terminals [254]. Somatic modulation of GABA A receptor-mediated fast inhibitory signaling in epileptiform activity was induced by calcineurin signaling in low-magnesium model of seizure in rat hippocampal neurons [31], suggesting a role of calcineurin in benzodiazepine resistance and the potential of its pharmacological targeting in status epilepticus.

Certainly, calcineurin/NFAT signaling involvement was also shown in pathogenic processes of other models of status epilepticus, including intracerebral injection of kainic acid [255], bicuculline [256], and pilocarpine [33]. Notably, calcineurin inhibitor ascomycin mediated anticonvulsant and neuroprotective effects, in different epilepsy models, including picrotoxin and latrunculin A models [257-259].

5.3. Emerging Challenge: Better Models? A growing number of studies are raising concerns about mechanistic reports of $\mathrm{Ca}^{2+}$-dependent and other signaling pathways from currently used models of neurodegenerative diseases, in particular transgenic animals and cell lines. A study addressing the suitability of rat striatal primordia-derived ST14A cell line for the study of voltage-gated $\mathrm{Ca}^{2+}$ channel of striatal medium spiny neurons called for serious caution on the assumption of the presence of complete signaling cascades of G-protein 
coupled receptors in cell lines [260]. Notably, ST14A cells were reported to lack PLC- $\beta 1$, a major effector of G-proteins for $\mathrm{Ca}^{2+}$ release from intracellular stores [59, 82], whose roles include (i) the regulation of forward locomotion in wild-type mice, among other dopamine receptor functions [261]; (ii) the mediation of $\mathrm{Ca}^{2+}$ flux required for mammalian sperm acrosome reaction [262]; and (iii) the mediation of the positive regulation of osteoblast differentiation [263]. In addition, most observations from studies in preclinical models of neurodegenerative diseases based on exogenous neurotoxins are not confirmed by clinical studies [264-266]. Similar observations emerge from studies in transgenic animals, where complex functional adaptations from gene knock-in or knock-out may limit the translational importance of findings [267-269]. In the case of neurodegenerative conditions, at least some of the controversy regarding changes in calcineurin/NFAT activity and/or expression appears to be due to the methodologies employed to measure activities and expression levels. Calcineurin, in particular, is highly sensitive to proteolysis during injury and neurodegeneration. However, most commercial antibodies to calcineurin only detect full-length calcineurin and miss the detection of high activity proteolytic fragments. Also, many studies have tended to measure calcineurin activity in whole brain tissue homogenates using commercially available phosphatase assays. While these kinds of assays are very good for kinetic analyses, they are very poor at assessing endogenous calcineurin activity toward endogenous substrates. Certainly, methodological challenges may have affected the quality of data generated by different groups. Although it appears that better models are needed, we also propose that better characterization of intracellular signaling in currently available and future experimental models may improve the translational importance of the findings.

\section{Concluding Remarks}

Calcineurin/NFAT pathway is pivotal during nervous system development and in various functions of mature central and peripheral nervous system. Notably, this signaling pathway is involved in myelination, corticogenesis, synaptogenesis, neuritogenesis, endosome trafficking, homeostatic synaptic plasticity, learning, and memory. Experimental evidence also shows that alterations in the activity of calcineurin/NFAT pathway and in activities of its endogenous regulators in the nervous system microvascular endothelial cells, astrocytes, microglia, Schwann cells, oligodendrocytes, and neurons participate in the pathogenesis of neurodegenerative diseases and conditions, but also psychotic disorders. Studies in transgenic animals and in cell lines also suggested that neurodegeneration-associated detrimental changes in calcineurin/NFAT signaling are NFAT isoform-selective as changes in NFATc3 and NFATc4, but not NFATc1 or NFATc2, are usually common. In addition pharmacological inhibition mitigated neuronal and astrocyte loss and improved cognitive functions in many models. However, other studies reported beneficial roles of calcineurin/NFAT in neurodegenerative diseases and conditions, in particular those reporting neurotoxic effects of pharmacological inhibition and increased endogenous regulation. These studies suggested that calcineurin can mediate both neuroprotective and neurodegenerative signals according to poorly understood determinant factors, which included the activation status of astrocytes in the central nervous system. Future studies should be devised to characterize better the factors determining the outcome of calcineurin/NFAT signaling in neurodegenerative diseases and conditions, as well as the downstream targets mediating the beneficial and detrimental effects of this signaling pathway, considering the implications for therapy.

\section{Competing Interests}

Authors have no conflict of interests.

\section{References}

[1] M. J. Berridge, M. D. Bootman, and H. L. Roderick, "Calcium signalling: dynamics, homeostasis and remodelling," Nature Reviews Molecular Cell Biology, vol. 4, no. 7, pp. 517-529, 2003.

[2] A. M. Cárdenas and F. D. Marengo, "How the stimulus defines the dynamics of vesicle pool recruitment, fusion mode, and vesicle recycling in neuroendocrine cells," Journal of Neurochemistry, vol. 137, no. 6, pp. 867-879, 2016.

[3] M. Buchholz and V. Ellenrieder, "An emerging role for $\mathrm{Ca}^{2+} /$ calcineurin/NFAT signaling in cancerogenesis," Cell Cycle, vol. 6, no. 1, pp. 16-19, 2007.

[4] A. Gafter-Gvili, B. Sredni, R. Gal, U. Gafter, and Y. Kalechman, "Cyclosporin A-induced hair growth in mice is associated with inhibition of calcineurin-dependent activation of NFAT in follicular keratinocytes," American Journal of Physiology-Cell Physiology, vol. 284, no. 6, pp. C1593-C1603, 2003.

[5] I. A. Graef, F. Chen, L. Chen, A. Kuo, and G. R. Crabtree, "Signals transduced by $\mathrm{Ca}^{2+} /$ calcineurin and NFATc $3 / \mathrm{c} 4$ pattern the developing vasculature," Cell, vol. 105, no. 7, pp. 863-875, 2001.

[6] J. J. Heit, Å. A. Apelqvist, X. Gu et al., "Calcineurin/NFAT signalling regulates pancreatic $\beta$-cell growth and function," Nature, vol. 443, no. 7109, pp. 345-349, 2006.

[7] V. Horsley, A. O. Aliprantis, L. Polak, L. H. Glimcher, and E. Fuchs, "NFATcl balances quiescence and proliferation of skin stem cells," Cell, vol. 132, no. 2, pp. 299-310, 2008.

[8] S.-C. Kao, H. Wu, J. Xie et al., "Calcineurin/NFAT signaling is required for neuregulin-regulated Schwann cell differentiation," Science, vol. 323, no. 5914, pp. 651-654, 2009.

[9] M. J. Kipanyula, A. Woodhoo, M. Rahman, D. Payne, K. R. Jessen, and R. Mirsky, "Calcineurin-nuclear factor of activated t cells regulation of Krox-20 expression in Schwann cells requires elevation of intracellular cyclic AMP," Journal of Neuroscience Research, vol. 91, no. 1, pp. 105-115, 2013.

[10] M. C. Lawrence, N. Borenstein-Auerbach, K. McGlynn et al., "NFAT targets signaling molecules to gene promoters in pancreatic $\beta$-cells," Molecular Endocrinology, vol. 29, no. 2, pp. $274-$ $288,2015$.

[11] C. Mammucari, A. T. D. Vignano, A. A. Sharov et al., "Integration of Notch 1 and calcineurin/NFAT signaling pathways in keratinocyte growth and differentiation control," Developmental Cell, vol. 8, no. 5, pp. 665-676, 2005.

[12] X.-S. Wu, Z. Zhang, W.-D. Zhao, D. Wang, F. Luo, and L.-G. $\mathrm{Wu}$, "Calcineurin is universally involved in vesicle endocytosis at neuronal and nonneuronal secretory cells," Cell Reports, vol. 7, no. 4, pp. 982-988, 2014. 
[13] J. C. Braz, O. F. Bueno, Q. Liang et al., "Targeted inhibition of p38 MAPK promotes hypertrophic cardiomyopathy through upregulation of calcineurin-NFAT signaling," The Journal of Clinical Investigation, vol. 111, no. 10, pp. 1475-1486, 2003.

[14] G. R. Crabtree and E. N. Olson, "NFAT signaling: choreographing the social lives of cells," Cell, vol. 109, no. 2, supplement 1, pp. S67-S79, 2002.

[15] T. Minami, S. Jiang, K. Schadler et al., "The calcineurin-NFATangiopoietin-2 signaling axis in lung endothelium is critical for the establishment of lung metastases," Cell Reports, vol. 4, no. 4, pp. 709-723, 2013.

[16] E. N. Olson and R. S. Williams, "Calcineurin signaling and muscle remodeling," Cell, vol. 101, no. 7, pp. 689-692, 2000.

[17] B. Pyrzynska, A. Lis, G. Mosieniak, and B. Kaminska, "Cyclosporin A-sensitive signaling pathway involving calcineurin regulates survival of reactive astrocytes," Neurochemistry International, vol. 38, no. 5, pp. 409-415, 2001.

[18] R. P. Sah, R. K. Dawra, and A. K. Saluja, "New insights into the pathogenesis of pancreatitis," Current Opinion in Gastroenterology, vol. 29, no. 5, pp. 523-530, 2013.

[19] B. Artegiani, A. M. de Jesus Domingues, S. Bragado Alonso et al., "Tox: a multifunctional transcription factor and novel regulator of mammalian corticogenesis," The EMBO Journal, vol. 34, no. 7, pp. 896-910, 2015.

[20] M. Fukuchi, A. Tabuchi, Y. Kuwana et al., "Neuromodulatory effect of G $\alpha$ s- or G $\alpha$ q-coupled G-protein-coupled receptor on NMDA receptor selectively activates the NMDA receptor/Ca ${ }^{2+} /$ calcineurin/cAMP response element-binding protein-regulated transcriptional coactivator 1 pathway to effectively induce brain-derived neurotrophic factor expression in neurons," The Journal of Neuroscience, vol. 35, no. 14, pp. 5606-5624, 2015.

[21] S. Sawamura, M. Hatano, Y. Takada et al., "Screening of transient receptor potential canonical channel activators identifies novel neurotrophic piperazine compounds," Molecular Pharmacology, vol. 89, no. 3, pp. 348-363, 2016.

[22] M. C. Serrano-Pérez, M. Fernández, F. Neria et al., "NFAT transcription factors regulate survival, proliferation, migration, and differentiation of neural precursor cells," Glia, vol. 63, no. 6, pp. 987-1004, 2015.

[23] M. Tsuda, "Gene regulation involved in the formation of longterm memory," Yakugaku Zasshi, vol. 135, no. 4, pp. 597-617, 2015.

[24] D. Dubey and B. E. Porter, "CRTC1 nuclear localization in the hippocampus of the pilocarpine-induced status epilepticus model of temporal lobe epilepsy," Neuroscience, vol. 320, pp. 4356, 2016.

[25] S. Kim, C. J. Violette, and E. B. Ziff, "Reduction of increased calcineurin activity rescues impaired homeostatic synaptic plasticity in presenilin 1 M146V mutant," Neurobiology of Aging, vol. 36, no. 12, pp. 3239-3246, 2015.

[26] B. Mojsa, S. Mora, J. P. Bossowski, I. Lassot, and S. Desagher, "Control of neuronal apoptosis by reciprocal regulation of NFATc3 and Trim17," Cell Death and Differentiation, vol. 22, no. 2, pp. 274-286, 2015.

[27] T. Boczek, B. Ferenc, M. Lisek, and L. Zylinska, "Regulation of GAP43/calmodulin complex formation via calcineurindependent mechanism in differentiated PC12 cells with altered PMCA isoforms composition," Molecular and Cellular Biochemistry, vol. 407, no. 1-2, pp. 251-262, 2015.

[28] R. S. Osorio, E. L. Ducca, M. E. Wohlleber et al., "Orexin$A$ is associated with increases in cerebrospinal fluid phosphorylated-tau in cognitively normal elderly subjects," Sleep, vol. 39, no. 6, pp. 1253-1260, 2016.

[29] A. P. Spira, C. E. Gonzalez, V. K. Venkatraman et al., "Sleep duration and subsequent cortical thinning in cognitively normal older adults," Sleep, vol. 39, no. 5, pp. 1121-1128, 2016.

[30] E. M. Anderson, T. Reeves, K. Kapernaros, J. K. Neubert, and R. M. Caudle, "Phosphorylation of the N-methyl-D-aspartate receptor is increased in the nucleus accumbens during both acute and extended morphine withdrawal," Journal of Pharmacology and Experimental Therapeutics, vol. 355, no. 3, pp. 496505, 2015.

[31] R. Eckel, B. Szulc, M. C. Walker, and J. T. Kittler, "Activation of calcineurin underlies altered trafficking of $\alpha 2$ subunit containing GABAA receptors during prolonged epileptiform activity," Neuropharmacology, vol. 88, pp. 82-90, 2015.

[32] G. Li, W. Yan, Y. Dang, J. Li, C. Liu, and J. Wang, “The role of calcineurin signaling in microcystin-LR triggered neuronal toxicity," Scientific Reports, vol. 5, Article ID 11271, 2015.

[33] J. Liu, X. Li, L. Chen, P. Xue, Q. Yang, and A. Wang, "Increased calcineurin expression after pilocarpine-induced status epilepticus is associated with brain focal edema and astrogliosis," International Journal of Neuroscience, vol. 126, no. 6, pp. 560567, 2016

[34] A. Madineni, Q. Alhadidi, and Z. A. Shah, "Cofilin inhibition restores neuronal cell death in oxygen-glucose deprivation model of ischemia," Molecular Neurobiology, vol. 53, no. 2, pp. 867-878, 2016

[35] E. Piccart, N. A. Courtney, S. Y. Branch, C. P. Ford, and M. J. Beckstead, "Neurotensin induces presynaptic depression of $\mathrm{D}_{2}$ dopamine autoreceptor-mediated neurotransmission in midbrain dopaminergic neurons," Journal of Neuroscience, vol. 35, no. 31, pp. 11144-11152, 2015.

[36] Z. Mei, P. Yan, X. Tan, S. Zheng, and B. Situ, “Transcriptional regulation of BACE1 by NFAT3 leads to enhanced amyloidogenic processing," Neurochemical Research, vol. 40, no. 4, pp. 829-836, 2015.

[37] H. Vihma, M. Luhakooder, P. Pruunsild, and T. Timmusk, "Regulation of different human NFAT isoforms by neuronal activity," Journal of Neurochemistry, vol. 137, no. 3, pp. 394-408, 2016.

[38] L.-J. Chen, Y.-J. Wang, J.-R. Chen, and G.-F. Tseng, "NMDA receptor triggered molecular cascade underlies compressioninduced rapid dendritic spine plasticity in cortical neurons," Experimental Neurology, vol. 266, pp. 86-98, 2015.

[39] J. L. Furman, P. Sompol, S. D. Kraner et al., "Blockade of astrocytic calcineurin/NFAT signaling helps to normalize hippocampal synaptic function and plasticity in a rat model of traumatic brain injury," The Journal of Neuroscience, vol. 36, no. 5, pp. 1502-1515, 2016.

[40] K. J. Gan and M. A. Silverman, "Dendritic and axonal mechanisms of $\mathrm{Ca}^{2+}$ elevation impair BDNF transport in $\mathrm{A} \beta$ oligomer-treated hippocampal neurons," Molecular Biology of the Cell, vol. 26, no. 6, pp. 1058-1071, 2015.

[41] M. Gratuze, A. Noël, C. Julien et al., “Tau hyperphosphorylation and deregulation of calcineurin inmousemodels of Huntington's disease," Human Molecular Genetics, vol. 24, no. 1, pp. 8699, 2015.

[42] H. C. Ho, T. S. Teo, R. Desai, and J. H. Wang, "Catalytic and regulatory properties of two forms of bovine heart cyclic nucleotide phosphodiesterase," Biochimica et Biophysica Acta (BBA)_Enzymology, vol. 429, no. 2, pp. 461-473, 1976. 
[43] J. H. Wang and R. Desai, "A brain protein and its effect on the CA2+-and protein modulator-activated cyclic nucleotide phosphodiesterase," Biochemical and Biophysical Research Communications, vol. 72, no. 3, pp. 926-932, 1976.

[44] H. Li, A. Rao, and P. G. Hogan, "Interaction of calcineurin with substrates and targeting proteins," Trends in Cell Biology, vol. 21, no. 2, pp. 91-103, 2011.

[45] F. Rusnak and P. Mertz, "Calcineurin: form and function," Physiological Reviews, vol. 80, no. 4, pp. 1483-1521, 2000.

[46] F. Mathieu, S. Miot, B. Etain et al., "Association between the PPP3CC gene, coding for the calcineurin gamma catalytic subunit, and bipolar disorder," Behavioral and Brain Functions, vol. 4, article 2, 2008.

[47] C. R. Williams and J. L. Gooch, "Calcineurin inhibitors and immunosuppression-a tale of two isoforms," Expert Reviews in Molecular Medicine, vol. 14, article e14, 2012.

[48] R. J. Bram, D. T. Hung, P. K. Martin, S. L. Schreiber, and G. R. Crabtree, "Identification of the immunophilins capable of mediating inhibition of signal transduction by cyclosporin A and FK506: roles of calcineurin binding and cellular location," Molecular and Cellular Biology, vol. 13, no. 8, pp. 4760-4769, 1993.

[49] N. Usuda, H. Arai, H. Sasaki et al., "Differential subcellular localization of neural isoforms of the catalytic subunit of calmodulin-dependent protein phosphatase (calcineurin) in central nervous system neurons: immunohistochemistry on formalin-fixed paraffin sections employing antigen retrieval by microwave irradiation," Journal of Histochemistry and Cytochemistry, vol. 44, no. 1, pp. 13-18, 1996.

[50] S. Mehta, N.-N. Aye-Han, A. Ganesan, L. Oldach, K. Gorshkov, and J. Zhang, "Calmodulin-controlled spatial decoding of oscillatory $\mathrm{Ca}^{2+}$ signals by calcineurin," eLife, vol. 3, article e03765, 2014.

[51] S. Mehta and J. Zhang, "Using a genetically encoded FRETbased reporter to visualize calcineurin phosphatase activity in living cells," Methods in Molecular Biology, vol. 1071, pp. 139-149, 2014.

[52] F. A. Anthony, M. A. Winkler, H. H. Edwards, and W. Y. Cheung, "Quantitative subcellular localization of calmodulin-dependent phosphatase in chick forebrain," The Journal of Neuroscience, vol. 8, no. 4, pp. 1245-1253, 1988.

[53] M. Boothby, "Cracking the code without rosetta: molecular regulation of calcium-stimulated gene transcription after $\mathrm{T}$ cell activation," The Journal of Immunology, vol. 185, no. 9, pp. 49694971, 2010.

[54] R. A. Schulz and K. E. Yutzey, "Calcineurin signaling and NFAT activation in cardiovascular and skeletal muscle development," Developmental Biology, vol. 266, no. 1, pp. 1-16, 2004.

[55] J.-P. Shaw, P. J. Utz, D. B. Durand, J. J. Toole, E. A. Emmel, and G. R. Crabtree, "Identification of a putative regulator of early T cell activation genes," Journal of Immunology, vol. 185, no. 9, pp. 4972-4975, 2010.

[56] H. Vihma, P. Pruunsild, and T. Timmusk, "Alternative splicing and expression of human and mouse NFAT genes," Genomics, vol. 92, no. 5, pp. 279-291, 2008.

[57] L. Jin, P. Sliz, L. Chen et al., "An asymmetric NFAT1 dimer on a pseudo-palindromic $\kappa$ B-like DNA site," Nature Structural Biology, vol. 10, no. 10, pp. 807-811, 2003.

[58] J. Aramburu, F. García-Cózar, A. Raghavan, H. Okamura, A. Rao, and P. G. Hogan, "Selective inhibition of NFAT activation by a peptide spanning the calcineurin targeting site of NFAT," Molecular Cell, vol. 1, no. 5, pp. 627-637, 1998.
[59] M. R. Müller, Y. Sasaki, I. Stevanovic et al., "Requirement for balanced Ca/NFAT signaling in hematopoietic and embryonic development," Proceedings of the National Academy of Sciences of the United States of America, vol. 106, no. 17, pp. 7034-7039, 2009.

[60] Z. Qian, P. G. Dougherty, T. Liu et al., "Structure-based optimization of a peptidyl inhibitor against calcineurin-nuclear factor of activated T cell (NFAT) interaction," Journal of Medicinal Chemistry, vol. 57, no. 18, pp. 7792-7797, 2014.

[61] Q. Wang, Y. Zhou, P. Rychahou, C. Liu, H. L. Weiss, and B. M. Evers, "NFAT5 represses canonical Wnt signaling via inhibition of $\beta$-catenin acetylation and participates in regulating intestinal cell differentiation," Cell Death and Disease, vol. 4, article e671, 2013.

[62] D. V. Faget, P. I. Lucena, B. K. Robbs, and J. P. B. Viola, "NFAT1 C-terminal domains are necessary but not sufficient for inducing cell death," PLOS ONE, vol. 7, no. 10, article e47868, 2012.

[63] M. De Lumley, D. J. Hart, M. A. Cooper, S. Symeonides, and J. M. Blackburn, "A biophysical characterisation of factors controlling dimerisation and selectivity in the NF- $\kappa$ B and NFAT families," Journal of Molecular Biology, vol. 339, no. 5, pp. 10591075, 2004.

[64] S. A. Wolfe, P. Zhou, V. Dötsch et al., "Unusual rel-like architecture in the DNA-binding domain of the transcription factor NFATc," Nature, vol. 385, no. 6612, pp. 172-176, 1997.

[65] D. L. Bates, K. K. B. Barthel, Y. Wu et al., "Crystal structure of NFAT bound to the HIV-1 LTR tandem $\kappa$ B enhancer element," Structure, vol. 16, no. 5, pp. 684-694, 2008.

[66] C.-H. Chen, V. A. Martin, N. M. Gorenstein, R. L. Geahlen, and C. B. Post, "Two closely spaced tyrosines regulate NFAT signaling in B cells via Syk association with Vav," Molecular and Cellular Biology, vol. 31, no. 14, pp. 2984-2996, 2011.

[67] E. Dirkx, M. M. Gladka, L. E. Philippen et al., "Nfat and miR-25 cooperate to reactivate the transcription factor Hand2 in heart failure," Nature Cell Biology, vol. 15, no. 11, pp. 1282-1293, 2013.

[68] H. Hu, I. Djuretic, M. S. Sundrud, and A. Rao, “Transcriptional partners in regulatory T cells: Foxp3, Runx and NFAT," Trends in Immunology, vol. 28, no. 8, pp. 329-332, 2007.

[69] S.-H. Im and A. Rao, "Activation and deactivation of gene expression by $\mathrm{Ca}^{2+} /$ calcineurin-NFAT-mediated signaling," Molecules and Cells, vol. 18, no. 1, pp. 1-9, 2004.

[70] F. Macián, C. López-Rodríguez, and A. Rao, "Partners in transcription: NFAT and AP-1," Oncogene, vol. 20, no. 19, pp. 2476-2489, 2001.

[71] K. Park, J.-H. Park, W.-J. Yang, J.-J. Lee, M.-J. Song, and H.-P. Kim, "Transcriptional activation of the IL31 gene by NFAT and STAT6," Journal of Leukocyte Biology, vol. 91, no. 2, pp. 245-257, 2012.

[72] Y. J. Shyu, C. D. Suarez, and C.-D. Hu, "Visualization of AP-1NF- $\kappa$ B ternary complexes in living cells by using a BiFC-based FRET," Proceedings of the National Academy of Sciences of the United States of America, vol. 105, no. 1, pp. 151-156, 2008.

[73] W. Wang, J. Lou, R. Zhong et al., "The roles of $\mathrm{Ca}^{2+} / \mathrm{NFAT}$ signaling genes in kawasaki disease: single-and multiple-risk genetic variants," Scientific Reports, vol. 4, article 5208, 2014.

[74] J. Zuo, F. Wu, Y. Liu et al., "MicroRNA transcriptome profile analysis in porcine muscle and the effect of miR-143 on the MYH7 gene and protein," PLoS ONE, vol. 10, no. 4, Article ID e0124873, 2015. 
[75] I. A. Graef, F. Wang, F. Charron et al., "Neurotrophins and netrins require calcineurin/NFAT signaling to stimulate outgrowth of embryonic axons," Cell, vol. 113, no. 5, pp. 657-670, 2003.

[76] G. L. Hernández, O. V. Volpert, M. A. Íñiguez et al., "Selective inhibition of vascular endothelial growth factor-mediated angiogenesis by cyclosporin A: roles of the nuclear factor of activated T cells and cyclooxygenase 2," Journal of Experimental Medicine, vol. 193, no. 5, pp. 607-620, 2001.

[77] M.-S. Kim, L. P. Shutov, A. Gnanasekaran et al., "Nerve growth factor (NGF) regulates activity of nuclear factor of activated Tcells (NFAT) in neurons via the phosphatidylinositol 3-kinase (PI3K)-Akt-glycogen synthase kinase $3 \beta$ (GSK3 $\beta$ ) pathway," The Journal of Biological Chemistry, vol. 289, no. 45, pp. 3134931360, 2014.

[78] E. H. Y. Tong, J.-J. Guo, S.-X. Xu et al., "Inducible nucleosome depletion at OREBP-binding-sites by hypertonic stress," PLoS ONE, vol. 4, no. 12, article e8435, 2009.

[79] A. Canellada, B. G. Ramirez, T. Minami, J. M. Redondo, and E. Cano, "Calcium/calcineurin signaling in primary cortical astrocyte cultures: Rcan1-4 and cyclooxygenase-2 as NFAT target genes," Glia, vol. 56, no. 7, pp. 709-722, 2008.

[80] V. Horsley and G. K. Pavlath, "NFAT: ubiquitous regulator of cell differentiation and adaptation," Journal of Cell Biology, vol. 156, no. 5, pp. 771-774, 2002.

[81] S. Reppert, E. Zinser, C. Holzinger, L. Sandrock, S. Koch, and S. Finotto, "NFATcl deficiency in T cells protects mice from experimental autoimmune encephalomyelitis," European Journal of Immunology, vol. 45, no. 5, pp. 1426-1440, 2015.

[82] D. Park, D.-Y. Jhon, C.-W. Lee, K.-H. Lee, and S. G. Rhee, "Activation of phospholipase $\mathrm{C}$ isozymes by $\mathrm{G}$ protein $\beta \gamma$ subunits," The Journal of Biological Chemistry, vol. 268, no. 7, pp. 4573-4576, 1993.

[83] D. Mandikian, E. Bocksteins, L. K. Parajuli et al., "Cell typespecific spatial and functional coupling between mammalian brain Kv2.1 $\mathrm{K}^{+}$channels and ryanodine receptors," Journal of Comparative Neurology, vol. 522, no. 15, pp. 3555-3574, 2014.

[84] F. J. Muñoz, J. A. Godoy, W. Cerpa, I. M. Poblete, J. P. HuidobroToro, and N. C. Inestrosa, "Wnt-5a increases NO and modulates NMDA receptor in rat hippocampal neurons," Biochemical and Biophysical Research Communications, vol. 444, no. 2, pp. 189194, 2014.

[85] W. C. Oh, L. K. Parajuli, and K. Zito, "Heterosynaptic structural plasticity on local dendritic segments of hippocampal CA1 neurons," Cell Reports, vol. 10, no. 2, pp. 162-169, 2015.

[86] T. Vervliet, J. B. Parys, and G. Bultynck, "Bcl-2 and FKBP12 bind to $\mathrm{IP}_{3}$ and ryanodine receptors at overlapping sites: the complexity of protein-protein interactions for channel regulation," Biochemical Society Transactions, vol. 43, pp. 396-404, 2015.

[87] Y. Yamazaki, S. Fujii, J.-I. Goto, H. Fujiwara, and K. Mikoshiba, "Activation of inositol 1,4,5-trisphosphate receptors during preconditioning low-frequency stimulation suppresses subsequent induction of long-term potentiation in hippocampal CA1 neurons," Neuroscience, vol. 311, pp. 195-206, 2015.

[88] H. Okamura, J. Aramburu, C. García-Rodríguez et al., "Concerted dephosphorylation of the transcription factor NFAT1 induces a conformational switch that regulates transcriptional activity," Molecular Cell, vol. 6, no. 3, pp. 539-550, 2000.

[89] Z.-H. Deng, T. S. Gomez, D. G. Osborne, C. A. PhillipsKrawczak, J.-S. Zhang, and D. D. Billadeau, "Nuclear FAM21 participates in NF- $\kappa \mathrm{B}$-dependent gene regulation in pancreatic cancer cells," Journal of Cell Science, vol. 128, no. 2, pp. 373-384, 2015.

[90] R. S. Lewis, "Calcium oscillations in T-cells: mechanisms and consequences for gene expression," Biochemical Society Transactions, vol. 31, no. 5, pp. 925-929, 2003.

[91] A. N. Mitchell, L. Jayakumar, I. Koleilat et al., "Brain expression of the calcineurin inhibitor RCAN1 (Adapt78)," Archives of Biochemistry and Biophysics, vol. 467, no. 2, pp. 185-192, 2007.

[92] A. Patel, N. Yamashita, M. Ascaño et al., "RCAN1 links impaired neurotrophin trafficking to aberrant development of the sympathetic nervous system in Down syndrome," Nature Communications, vol. 6, Article ID 10119, 2015.

[93] P. G. Hogan, L. Chen, J. Nardone, and A. Rao, "Transcriptional regulation by calcium, calcineurin, and NFAT," Genes and Development, vol. 17, no. 18, pp. 2205-2232, 2003.

[94] E. Kilanczyk, A. Filipek, and M. Hetman, "Calcyclin-binding protein/Siah-1-interacting protein as a regulator of transcriptional responses in brain cells," Journal of Neuroscience Research, vol. 93, no. 1, pp. 75-81, 2015.

[95] P. G. Del Arco, S. Martínez-Martínez, J. L. Maldonado, I. Ortega-Pérez, and J. M. Redondo, "A role for the p38 MAP kinase pathway in the nuclear shuttling of NFATp," Journal of Biological Chemistry, vol. 275, no. 18, pp. 13872-13878, 2000.

[96] P. J. Dittmer, M. L. Dell'Acqua, and W. A. Sather, " $\mathrm{Ca}^{2+}$ / calcineurin-dependent inactivation of neuronal L-type $\mathrm{Ca}^{2+}$ channels requires priming by AKAP-anchored protein kinase A," Cell Reports, vol. 7, no. 5, pp. 1410-1416, 2014.

[97] B. K. Samelson, B. B. Gore, J. L. Whiting et al., "A-kinase anchoring protein 79/150 recruits protein kinase $C$ to phosphorylate roundabout receptors," The Journal of Biological Chemistry, vol. 290, no. 22, pp. 14107-14119, 2015.

[98] Y. Wen, P. Zhou, L. Liu, Z. Wang, Y. Zhang, and J. Liang, "Effect of the knockdown of Cabin1 on p53 in glomerular podocyte," Journal of Receptors and Signal Transduction, vol. 36, no. 2, pp. 173-180, 2016.

[99] J.-K. Yi, H.-J. Kim, D.-H. Yu et al., "Regulation of inflammatory responses and fibroblast-like synoviocyte apoptosis by calcineurin-binding protein 1 in mice with collagen-induced arthritis," Arthritis and Rheumatism, vol. 64, no. 7, pp. 21912200, 2012.

[100] F. Di Sole, K. Vadnagara, O. W. Moe, and V. Babich, "Calcineurin homologous protein: a multifunctional $\mathrm{Ca}^{2+}$-binding protein family," American Journal of Physiology-Renal Physiology, vol. 303, no. 2, pp. F165-F179, 2012.

[101] Y. Kobayashi, R. da Silva, H. Kumanogoh et al., "Ganglioside contained in the neuronal tissue-enriched acidic protein of 22 $\mathrm{kDa}$ (NAP-22) fraction prepared from the detergent-resistant membrane microdomain of rat brain inhibits the phosphatase activity of calcineurin," Journal of Neuroscience Research, vol. 93, no. 9, pp. 1462-1470, 2015.

[102] X. Lin, R. A. Sikkink, F. Rusnak, and D. L. Barber, "Inhibition of calcineurin phosphatase activity by a calcineurin B homologous protein," The Journal of Biological Chemistry, vol. 274, no. 51, pp. 36125-36131, 1999.

[103] R. B. Vega, J. Yang, B. A. Rothermel, R. Bassel-Duby, and R. S. Williams, "Multiple domains of MCIP1 contribute to inhibition of calcineurin activity," Journal of Biological Chemistry, vol. 277, no. 33, pp. 30401-30407, 2002.

[104] C. Brandt, V. Pavlovic, A. Radbruch, M. Worm, and R. Baumgrass, "Low-dose cyclosporine A therapy increases the regulatory T cell population in patients with atopic dermatitis," Allergy, vol. 64, no. 11, pp. 1588-1596, 2009. 
[105] J. Cury Martins, C. Martins, V. Aoki, A. F. T. Gois, H. A. Ishii, and E. M. K. da Silva, "Topical tacrolimus for atopic dermatitis," The Cochrane Database of Systematic Reviews, no. 7, Article ID CD009864, 2015.

[106] B. Höcker and B. Tönshoff, "Calcineurin inhibitor-free immunosuppression in pediatric renal transplantation: a viable option?" Pediatric Drugs, vol. 13, no. 1, pp. 49-69, 2011.

[107] J. M. Tredger, N. W. Brown, and A. Dhawan, "Calcineurin inhibitor sparing in paediatric solid organ transplantation: managing the efficacy/toxicity conundrum," Drugs, vol. 68, no. 10, pp. 1385-1414, 2008.

[108] B. Kaminska, I. Figiel, B. Pyrzynska, R. Czajkowski, and G. Mosieniak, "Treatment of hippocampal neurons with cyclosporin A results in calcium overload and apoptosis which are independent on NMDA receptor activation," British Journal of Pharmacology, vol. 133, no. 7, pp. 997-1004, 2001.

[109] J. Klawitter, S. Gottschalk, C. Hainz, D. Leibfritz, U. Christians, and N. J. Serkova, "Immunosuppressant neurotoxicity in rat brain models: oxidative stress and cellular metabolism," Chemical Research in Toxicology, vol. 23, no. 3, pp. 608-619, 2010.

[110] R. Gómez-Sintes and J. J. Lucas, "NFAT/Fas signaling mediates the neuronal apoptosis and motor side effects of GSK-3 inhibition in a mouse model of lithium therapy," The Journal of Clinical Investigation, vol. 120, no. 7, pp. 2432-2445, 2010.

[111] L. Bica, J. R. Liddell, P. S. Donnelly et al., "Neuroprotective copper bis(thiosemicarbazonato) complexes promote neurite elongation," PLoS ONE, vol. 9, no. 2, Article ID e90070, 2014.

[112] T. Johanssen, N. Suphantarida, P. S. Donnelly et al., "РBT2 inhibits glutamate-induced excitotoxicity in neurons through metal-mediated preconditioning," Neurobiology of Disease, vol. 81, pp. 176-185, 2015.

[113] F. Rapisarda, G. Portale, S. Ferrario et al., "Magnesium, calcium and potassium: 'no one was born alone," Giornale Italiano di Nefrologia, vol. 33, 2016.

[114] S.-R. Chen, Y.-M. Hu, H. Chen, and H.-L. Pan, "Calcineurin inhibitor induces pain hypersensitivity by potentiating pre- and postsynaptic NMDA receptor activity in spinal cords," Journal of Physiology, vol. 592, no. 1, pp. 215-227, 2014.

[115] S.-R. Chen, H.-Y. Zhou, H. S. Byun, H. Chen, and H.-L. Pan, "Casein kinase II regulates $N$-methyl-D-aspartate receptor activity in spinal cords and pain hypersensitivity induced by nerve injury," The Journal of Pharmacology and Experimental Therapeutics, vol. 350, no. 2, pp. 301-312, 2014.

[116] G. Miletic, J. L. Hermes, G. L. Bosscher, B. M. Meier, and V. Miletic, "Protein kinase C gamma-mediated phosphorylation of GluAl in the postsynaptic density of spinal dorsal horn neurons accompanies neuropathic pain, and dephosphorylation by calcineurin is associated with prolonged analgesia," PAIN, vol. 156, no. 12, pp. 2514-2520, 2015.

[117] Y.-M. Hu, S.-R. Chen, H. Chen, and H.-L. Pan, "Casein kinase II inhibition reverses pain hypersensitivity and potentiated spinal $\mathrm{N}$-methyl-D-aspartate receptor activity caused by calcineurin inhibitor," Journal of Pharmacology and Experimental Therapeutics, vol. 349, no. 2, pp. 239-247, 2014.

[118] H. J. Solinski, F. Petermann, K. Rothe, I. Boekhoff, T. Gudermann, and A. Breit, "Human Mas-related G protein-coupled receptors-X1 induce chemokine receptor 2 expression in rat dorsal root ganglia neurons and release of chemokine ligand 2 from the human LAD-2 mast cell line," PLoS ONE, vol. 8, no. 3, Article ID e58756, 2013.
[119] M. H. A. Roehrl, J. Y. Wang, and G. Wagner, "Discovery of small-molecule inhibitors of the NFAT-calcineurin interaction by competitive high-throughput fluorescence polarization screening," Biochemistry, vol. 43, no. 51, pp. 16067-16075, 2004.

[120] K. Takeuchi, M. H. A. Roehrl, Z.-Y. J. Sun, and G. Wagner, "Structure of the calcineurin-NFAT complex: defining a T cell activation switch using solution NMR and crystal coordinates," Structure, vol. 15, no. 5, pp. 587-597, 2007.

[121] B. Ding, W. Wang, T. Selvakumar et al., “Temporal regulation of nuclear factor one occupancy by calcineurin/NFAT governs a voltage-sensitive developmental switch in late maturing neurons," The Journal of Neuroscience, vol. 33, no. 7, pp. 2860-2872, 2013.

[122] A. Cho, Y. Tang, J. Davila et al., "Calcineurin signaling regulates neural induction through antagonizing the BMP pathway," Neuron, vol. 82, no. 1, pp. 109-124, 2014.

[123] M. D. Cahalan, "STIMulating store-operated $\mathrm{Ca}^{2+}$ entry," Nature Cell Biology, vol. 11, no. 6, pp. 669-677, 2009.

[124] R. Palty, A. Raveh, I. Kaminsky, R. Meller, and E. Reuveny, "SARAF inactivates the store operated calcium entry machinery to prevent excess calcium refilling," Cell, vol. 149, no. 2, pp. 425438, 2012.

[125] A. Somasundaram, A. K. Shum, H. J. McBride et al., "Storeoperated CRAC channels regulate gene expression and proliferation in neural progenitor cells," The Journal of Neuroscience, vol. 34, no. 27, pp. 9107-9123, 2014.

[126] J. D. Ulrich, M.-S. Kim, P. R. Houlihan et al., "Distinct activation properties of the nuclear factor of activated T-cells (NFAT) isoforms NFATc3 and NFATc4 in neurons," Journal of Biological Chemistry, vol. 287, no. 45, pp. 37594-37609, 2012.

[127] J. A. Filosa, M. T. Nelson, and L. V. Gonzalez Bosc, "Activity-dependent NFATc3 nuclear accumulation in pericytes from cortical parenchymal microvessels," American Journal of Physiology-Cell Physiology, vol. 293, no. 6, pp. C1797-C1805, 2007.

[128] H. Q. Yan, S. S. Shin, X. Ma, Y. Li, and C. E. Dixon, "Differential effect of traumatic brain injury on the nuclear factor of activated T Cells C3 and C4 isoforms in the rat hippocampus," Brain Research, vol. 1548, pp. 63-72, 2014.

[129] M. Fukuchi, Y. Kirikoshi, A. Mori et al., "Excitatory GABA induces BDNF transcription via CRTC1 and phosphorylated CREB-related pathways in immature cortical cells," Journal of Neurochemistry, vol. 131, no. 2, pp. 134-146, 2014.

[130] F. Niwa, H. Bannai, M. Arizono, K. Fukatsu, A. Triller, and K. Mikoshiba, "Gephyrin-independent GABA ${ }_{\mathrm{A}} \mathrm{R}$ mobility and clustering during plasticity," PLoS ONE, vol. 7, no. 4, Article ID e36148, 2012.

[131] G. C. Stefos, U. Soppa, M. Dierssen, and W. Becker, "NGF upregulates the plasminogen activation inhibitor-1 in neurons via the calcineurin/NFAT pathway and the Down syndromerelated proteins DYRK1A and RCAN1 attenuate this effect," PLoS ONE, vol. 8, no. 6, Article ID e67470, 2013.

[132] C.-Y. Wang, H.-C. Lin, Y.-P. Song et al., "Protein kinase Cdependent growth-associated protein 43 phosphorylation regulates gephyrin aggregation at developing GABAergic synapses," Molecular and Cellular Biology, vol. 35, no. 10, pp. 1712-1726, 2015.

[133] F. J. Caballero, R. Soler-Torronteras, M. Lara-Chica et al., "AM404 inhibits NFAT and NF- $\kappa$ B signaling pathways and impairs migration and invasiveness of neuroblastoma cells," European Journal of Pharmacology, vol. 746, pp. 221-232, 2015. 
[134] A. E. Chávez, V. M. Hernández, A. Rodenas-Ruano, C. Savio Chan, and P. E. Castillo, "Compartment-specific modulation of GABAergic synaptic transmission by TRPV1 channels in the dentate gyrus," The Journal of Neuroscience, vol. 34, no. 50, pp. 16621-16629, 2014.

[135] T. Hayama, J. Noguchi, S. Watanabe et al., "GABA promotes the competitive selection of dendritic spines by controlling local $\mathrm{Ca}^{2+}$ signaling," Nature Neuroscience, vol. 16, no. 10, pp. 14091416, 2013.

[136] H. Toyoda, M. Saito, H. Sato et al., "Enhanced desensitization followed by unusual resensitization in $\mathrm{GABA}_{\mathrm{A}}$ receptors in phospholipase C-related catalytically inactive protein-1/2 double-knockout mice," Pflügers Archiv, vol. 467, no. 2, pp. 267284, 2014.

[137] B. Calabrese and S. Halpain, "Differential targeting of dynamin1 and dynamin-3 to nerve terminals during chronic suppression of neuronal activity," Molecular and Cellular Neuroscience, vol. 68, pp. 36-45, 2015.

[138] D. Suo, J. Park, A. W. Harrington, L. S. Zweifel, S. Mihalas, and C. D. Deppmann, "Coronin-1 is a neurotrophin endosomal effector that is required for developmental competition for survival," Nature Neuroscience, vol. 17, no. 1, pp. 36-45, 2014.

[139] J. Lim, H.-S. Choi, and H. J. Choi, "Estrogen-related receptor gamma regulates dopaminergic neuronal phenotype by activating GSK3 $\beta$ /NFAT signaling in SH-SY5Y cells," Journal of Neurochemistry, vol. 133, no. 4, pp. 544-557, 2015.

[140] J. R. Cottrell, B. Li, J. W. Kyung et al., "Calcineurin A $\gamma$ is a functional phosphatase that modulates synaptic vesicle endocytosis," The Journal of Biological Chemistry, vol. 291, no. 4, pp. 1948-1956, 2016.

[141] D. C. Hondius, P. van Nierop, K. W. Li et al., "Profiling the human hippocampal proteome at all pathologic stages of Alzheimer's disease," Alzheimer's \& Dementia, vol. 12, no. 6, pp. 654-668, 2016.

[142] G. Pigino, G. Morfini, Y. Atagi et al., "Disruption of fast axonal transport is a pathogenic mechanism for intraneuronal amyloid beta," Proceedings of the National Academy of Sciences of the United States of America, vol. 106, no. 14, pp. 5907-5912, 2009.

[143] E. M. Ramser, K. J. Gan, H. Decker et al., "Amyloid- $\beta$ oligomers induce tau-independent disruption of BDNF axonal transport via calcineurin activation in cultured hippocampal neurons," Molecular Biology of the Cell, vol. 24, no. 16, pp. 2494-2505, 2013.

[144] P. Toglia, K. H. Cheung, D. D. Mak, and G. Ullah, "Impaired mitochondrial function due to familial Alzheimer's diseasecausing presenilins mutants via $\mathrm{Ca}^{2+}$ disruptions," Cell Calcium, vol. 59, no. 5, pp. 240-250, 2016.

[145] R. Pigeat, P. Chausson, F. M. Dreyfus, N. Leresche, and R. C. Lambert, "Sleep slow wave-related homo and heterosynaptic LTD of intrathalamic GABA $\mathrm{A}_{\mathrm{A}}$ ergic synapses: involvement of Ttype $\mathrm{Ca}^{2+}$ channels and metabotropic glutamate receptors," The Journal of Neuroscience, vol. 35, no. 1, pp. 64-73, 2015.

[146] D. M. Raizen, J. E. Zimmerman, M. H. Maycock et al., "Lethargus is a Caenorhabditis elegans sleep-like state," Nature, vol. 451, pp. 569-572, 2008.

[147] C.-O. Wong, K. Chen, Y. Lin et al., "A TRPV channel in drosophila motor neurons regulates presynaptic resting $\mathrm{Ca}^{2+}$ levels, synapse growth, and synaptic transmission," Neuron, vol. 84, no. 4, pp. 764-777, 2014.

[148] M. D. Evans, A. S. Dumitrescu, D. L. H. Kruijssen, S. E. Taylor, and M. S. Grubb, "Rapid modulation of axon initial segment length influences repetitive spike firing," Cell Reports, vol. 13, no. 6, pp. 1233-1245, 2015.
[149] K. L. Arendt, Z. Zhang, S. Ganesan et al., "Calcineurin mediates homeostatic synaptic plasticity by regulating retinoic acid synthesis," Proceedings of the National Academy of Sciences of the United States of America, vol. 112, no. 42, pp. E5744-E5752, 2015.

[150] Y. Hatanaka, Y. Hojo, H. Mukai et al., "Rapid increase of spines by dihydrotestosterone and testosterone in hippocampal neurons: dependence on synaptic androgen receptor and kinase networks," Brain Research, vol. 1621, pp. 121-132, 2015.

[151] Y. Hasegawa, Y. Hojo, H. Kojima et al., "Estradiol rapidly modulates synaptic plasticity of hippocampal neurons: involvement of kinase networks," Brain Research, vol. 1621, pp. 147-161, 2015.

[152] H. Zhang, J. Liu, S. Sun, E. Pchitskaya, E. Popugaeva, and I. Bezprozvanny, "Calcium signaling, excitability, and synaptic plasticity defects in a mouse model of Alzheimer's disease," Journal of Alzheimer's Disease, vol. 45, no. 2, pp. 561-580, 2015.

[153] A.-H. Chou, Y.-L. Chen, S.-H. Hu, Y.-M. Chang, and H.L. Wang, "Polyglutamine-expanded ataxin-3impairslong-term depression in Purkinje neurons of SCA3 transgenic mouse byinhibiting HAT andimpairing histone acetylation," Brain Research, vol. 1583, no. 1, pp. 220-229, 2014.

[154] J. Zhang and M. S. Shapiro, "Activity-dependent transcriptional regulation of M-Type (Kv7) $\mathrm{K}^{+}$channels by AKAP79/150mediated NFAT actions," Neuron, vol. 76, no. 6, pp. 1133-1146, 2012.

[155] A. D. Williams, S. Jung, and N. P. Poolos, "Protein kinase C bidirectionally modulates $I_{\mathrm{h}}$ and hyperpolarization-activated cyclic nucleotide-gated (HCN) channel surface expression in hippocampal pyramidal neurons," Journal of Physiology, vol. 593, no. 13, pp. 2779-2792, 2015.

[156] V. García-Morales, F. Montero, D. González-Forero et al., "Membrane-derived phospholipids control synaptic neurotransmission and plasticity," PLoS Biology, vol. 13, no. 5, Article ID e1002153, 2015.

[157] S. Kim and E. B. Ziff, "Calcineurin mediates synaptic scaling via synaptic trafficking of $\mathrm{Ca}^{2+}$-permeable AMPA receptors," PLoS Biology, vol. 12, no. 7, Article ID e1001900, 2014.

[158] T. Yoshida and M. Mishina, "Distinct roles of calcineurinnuclear factor of activated $\mathrm{T}$ cells and protein kinase A-cAMP response element-binding protein signaling in presynaptic differentiation," Journal of Neuroscience, vol. 25, no. 12, pp. 30673079, 2005.

[159] J. G. Murphy, J. L. Sanderson, J. A. Gorski et al., "AKAPanchored PKA maintains neuronal L-type calcium channel activity and NFAT transcriptional signaling," Cell Reports, vol. 7, no. 5, pp. 1577-1588, 2014.

[160] H. Li, M. D. Pink, J. G. Murphy, A. Stein, M. L. Dell’Acqua, and P. G. Hogan, "Balanced interactions of calcineurin with AKAP79 regulate $\mathrm{Ca}^{2+}$-calcineurin-NFAT signaling," Nature Structural and Molecular Biology, vol. 19, no. 3, pp. 337-345, 2012.

[161] S. R. Seo, S. S. Kim, and K. C. Chung, "Activation of adenylate cyclase by forskolin increases the protein stability of RCAN1 (DSCR1 or Adapt78)," FEBS Letters, vol. 583, no. 19, pp. 31403144, 2009.

[162] S. Deheshi, B. Dabiri, S. Fan, M. Tsang, and G. L. Rintoul, "Changes in mitochondrial morphology induced by calcium or rotenone in primary astrocytes occur predominantly through ros-mediated remodeling," Journal of Neurochemistry, vol. 133, no. 5, pp. 684-699, 2015.

[163] A. M. Slupe, R. A. Merrill, K. H. Flippo, M. A. Lobas, J. C. D. Houtman, and S. Strack, "A calcineurin docking motif (LXVP) in dynamin-related protein 1 contributes to mitochondrial 
fragmentation and ischemic neuronal injury," The Journal of Biological Chemistry, vol. 288, no. 17, pp. 12353-12365, 2013.

[164] W.-D. C. Krenz, E. W. Rodgers, and D. J. Baro, “Tonic 5nM DA stabilizes neuronal output by enabling bidirectional activitydependent regulation of the hyperpolarization activated current via PKA and calcineurin," PLOS ONE, vol. 10, no. 2, Article ID e0117965, 2015.

[165] K. Bacallao and P. V. Monje, "Requirement of cAMP signaling for Schwann cell differentiation restricts the onset of myelination," PLoS ONE, vol. 10, no. 2, Article ID e0116948, 2015.

[166] R. Nagarajan, J. Svaren, N. Le, T. Araki, M. Watson, and J. Milbrandt, "EGR2 mutations in inherited neuropathies dominantnegatively inhibit myelin gene expression," Neuron, vol. 30, no. 2, pp. 355-368, 2001.

[167] K. Bacallao and P. V. Monje, "Opposing roles of PKA and EPAC in the cAMP-dependent regulation of schwann cell proliferation and differentiation," PLoS ONE, vol. 8, no. 12, Article ID e82354, 2013.

[168] M. Finzsch, S. Schreiner, T. Kichko et al., "Sox10 is required for Schwann cell identity and progression beyond the immature Schwann cell stage," Journal of Cell Biology, vol. 189, no. 4, pp. 701-712, 2010.

[169] R. I. Peirano, D. E. Goerich, D. Riethmacher, and M. Wegner, "Protein zero gene expression is regulated by the glial transcription factor Sox10," Molecular and Cellular Biology, vol. 20, no. 9, pp. 3198-3209, 2000.

[170] A. Rao, "Signaling to gene expression: calcium, calcineurin and NFAT," Nature Immunology, vol. 10, no. 1, pp. 3-5, 2009.

[171] S.-W. Jang and J. Svaren, "Induction of myelin protein zero by early growth response 2 through upstream and intragenic elements," The Journal of Biological Chemistry, vol. 284, no. 30, pp. 20111-20120, 2009.

[172] H. Fansa, G. Keilhoff, T. Horn, S. Altmann, G. Wolf, and W. Schneider, "Stimulation of Schwann cell proliferation and axonal regeneration by FK 506," Restorative Neurology and Neuroscience, vol. 16, no. 2, pp. 77-86, 2000.

[173] M.-S. Guzmán-Lenis, C. Vallejo, X. Navarro, and C. Casas, "Analysis of FK506-mediated protection in an organotypic model of spinal cord damage: heat shock protein 70 levels are modulated in microglial cells," Neuroscience, vol. 155, no. 1, pp. 104-113, 2008.

[174] S. Nottingham, P. Knapp, and J. Springer, "Fk506 treatment inhibits caspase-3 activation and promotes oligodendroglial survival following traumatic spinal cord injury," Experimental Neurology, vol. 177, no. 1, pp. 242-251, 2002.

[175] L. Dietz, F. Frommer, A.-L. Vogel et al., "NFAT1 deficit and NFAT2 deficit attenuate EAE via different mechanisms," European Journal of Immunology, vol. 45, no. 5, pp. 1377-1389, 2015.

[176] S. Ghosh, S. B. Koralov, I. Stevanovic et al., "Hyperactivation of nuclear factor of activated T cells 1 (NFAT1) in T cells attenuates severity of murine autoimmune encephalomyelitis," Proceedings of the National Academy of Sciences of the United States of America, vol. 107, no. 34, pp. 15169-15174, 2010.

[177] H. M. Abdul, J. L. Furman, M. A. Sama, D. M. Mathis, and C. M. Norris, "NFATs and Alzheimer's disease," Molecular and Cellular Pharmacology, vol. 2, no. 1, pp. 7-14, 2010.

[178] C. M. Norris, I. Kadish, E. M. Blalock et al., "Calcineurin triggers reactive/inflammatory processes in astrocytes and is upregulated in aging and Alzheimer's models," Journal of Neuroscience, vol. 25, no. 18, pp. 4649-4658, 2005.
[179] M. Berrocal, I. Corbacho, M. Vázquez-Hernández, J. Ávila, M. R. Sepúlveda, and A. M. Mata, "Inhibition of PMCA activity by tau as a function of aging and Alzheimer's neuropathology," Biochimica et Biophysica Acta-Molecular Basis of Disease, vol. 1852, no. 7, pp. 1465-1476, 2015.

[180] M. Berrocal, D. Marcos, M. R. Sepúlveda, M. Pérez, J. Ávila, and A. M. Mata, "Altered $\mathrm{Ca}^{2+}$ dependence of synaptosomal plasma membrane $\mathrm{Ca}^{2+}$-ATPase in human brain affected by Alzheimer's disease," The FASEB Journal, vol. 23, no. 6, pp. 18261834, 2009.

[181] C. Conejero-Goldberg, J. J. Gomar, T. Bobes-Bascaran et al., "APOE2 enhances neuroprotection against Alzheimer's disease through multiple molecular mechanisms," Molecular Psychiatry, vol. 19, no. 11, pp. 1243-1250, 2014.

[182] H. Hayashi, R. B. Campenot, D. E. Vance, and J. E. Vance, "Protection of neurons from apoptosis by apolipoprotein Econtaining lipoproteins does not require lipoprotein uptake and involves activation of phospholipase $\mathrm{C} \gamma 1$ and inhibition of calcineurin," The Journal of Biological Chemistry, vol. 284, no. 43, pp. 29605-29613, 2009.

[183] M. Shinohara, T. Kanekiyo, L. Yang et al., "APOE2 eases cognitive decline during aging: clinical and preclinical evaluations," Annals of Neurology, vol. 79, no. 5, pp. 758-774, 2016.

[184] H.-Y. Wu, E. Hudry, T. Hashimoto et al., "Distinct dendritic spine and nuclear phases of calcineurin activation after exposure to amyloid- $\beta$ revealed by a novel fluorescence resonance energy transfer assay," Journal of Neuroscience, vol. 32, no. 15, pp. 5298-5309, 2012.

[185] J. R. Casanova, M. Nishimura, and J. W. Swann, “The effects of early-life seizures on hippocampal dendrite development and later-life learning and memory," Brain Research Bulletin, vol. 103, pp. 39-48, 2014.

[186] H. M. Abdul, M. A. Sama, J. L. Furman et al., "Cognitive decline in Alzheimer's disease is associated with selective changes in calcineurin/NFAT signaling," The Journal of Neuroscience, vol. 29, no. 41, pp. 12957-12969, 2009.

[187] K. Bromley-Brits and W. Song, "The role of TMP21 in trafficking and amyloid- $\beta$ precursor protein (APP) processing in Alzheimer's disease," Current Alzheimer Research, vol. 9, no. 4, pp. 411-424, 2012.

[188] A. A. Grolla, G. Fakhfouri, G. Balzaretti et al., "A $\beta$ leads to $\mathrm{Ca}^{2+}$ signaling alterations and transcriptional changes in glial cells," Neurobiology of Aging, vol. 34, no. 2, pp. 511-522, 2013.

[189] D. Lim, A. Iyer, V. Ronco et al., "Amyloid beta deregulates astroglial mGluR5-mediated calcium signaling via calcineurin and Nf-kB," Glia, vol. 61, no. 7, pp. 1134-1145, 2013.

[190] S. Liu, S. Zhang, K. Bromley-Brits et al., "Transcriptional regulation of TMP21 by NFAT," Molecular Neurodegeneration, vol. 6, article 21, 2011.

[191] J. Luo, L. Sun, X. Lin et al., "A calcineurin- and NFAT-dependent pathway is involved in $\alpha$-synuclein-induced degeneration of midbrain dopaminergic neurons," Human Molecular Genetics, vol. 23, no. 24, pp. 6567-6574, 2014.

[192] G. Caraveo, P. K. Auluck, L. Whitesell et al., "Calcineurin determines toxic versus beneficial responses to $\alpha$-synuclein," Proceedings of the National Academy of Sciences of the United States of America, vol. 111, no. 34, pp. E3544-E3552, 2014.

[193] E. C. Miller, P. J. Teravskis, B. W. Dummer, X. Zhao, R. L. Huganir, and D. Liao, "Tau phosphorylation and tau mislocalization mediate soluble $\mathrm{A} \beta$ oligomer-induced AMPA glutamate receptor signaling deficits," European Journal of Neuroscience, vol. 39, no. 7, pp. 1214-1224, 2014. 
[194] S.-H. Ma, Q.-X. Zhuang, W.-X. Shen, Y.-P. Peng, and Y.-H. Qiu, "Interleukin-6 reduces NMDAR-mediated cytosolic Ca ${ }^{2+}$ overload and neuronal death via JAK/CaN signaling," Cell Calcium, vol. 58, no. 3, pp. 286-295, 2015.

[195] K. Watanabe, K. Uemura, M. Asada et al., “The participation of insulin-like growth factor-binding protein 3 released by astrocytes in the pathology of Alzheimer's disease," Molecular Brain, vol. 8, article 82, 2015.

[196] G. Dobrowolny, C. Giacinti, L. Pelosi et al., "Muscle expression of a local Igf-1 isoform protects motor neurons in an ALS mouse model," Journal of Cell Biology, vol. 168, no. 2, pp. 193-199, 2005.

[197] A. M. Fernandez, S. Jimenez, M. Mecha et al., "Regulation of the phosphatase calcineurin by insulin-like growth factor I unveils a key role of astrocytes in Alzheimer's pathology," Molecular Psychiatry, vol. 17, no. 7, pp. 705-718, 2012.

[198] S. Pons and I. Torres-Aleman, "Insulin-like growth factor-I stimulates dephosphorylation of $\mathrm{I} \kappa \mathrm{B}$ through the serine phosphatase calcineurin (protein phosphatase 2B)," Journal of Biological Chemistry, vol. 275, no. 49, pp. 38620-38625, 2000.

[199] T. Takadera and T. Ohyashiki, "Caspase-dependent apoptosis induced by calcineurin inhibitors was prevented by glycogen synthase kinase- 3 inhibitors in cultured rat cortical cells," Brain Research, vol. 1133, no. 1, pp. 20-26, 2007.

[200] S. Á. Álvarez, A. Blanco, M. Fresno, and M. Á. MuñozFernández, "TNF- $\alpha$ contributes to caspase-3 independent apoptosis in neuroblastoma cells: role of NFAT," PLoS ONE, vol. 6, no. 1, Article ID e16100, 2011.

[201] A. Canellada, E. Cano, L. Sánchez-Ruiloba, F. Zafra, and J. M. Redondo, "Calcium-dependent expression of TNF- $\alpha$ in neural cells is mediated by the calcineurin/NFAT pathway," Molecular and Cellular Neuroscience, vol. 31, no. 4, pp. 692-701, 2006.

[202] B. Ma, J. Yu, C. Xie et al., "Toll-like receptors promote mitochondrial translocation of nuclear transcription factor nuclear factor of activated T-cells in prolonged microglial activation," The Journal of Neuroscience, vol. 35, no. 30, pp. 10799-10814, 2015.

[203] A. M. Fernandez, S. Fernandez, P. Carrero, M. Garcia-Garcia, and I. Torres-Aleman, "Calcineurin in reactive astrocytes plays a key role in the interplay between proinflammatory and antiinflammatory signals," The Journal of Neuroscience, vol. 27, no. 33, pp. 8745-8756, 2007.

[204] B. Kim, H.-K. Jeong, J.-H. Kim, S. Y. Lee, I. Jou, and E.-H. Joe, "Uridine 5/-diphosphate induces chemokine expression in microglia and astrocytes through activation of the P2Y6 receptor," Journal of Immunology, vol. 186, no. 6, pp. 3701-3709, 2011.

[205] J. L. Furman, D. M. Sama, J. C. Gant et al., "Targeting astrocytes Ameliorates neurologic changes in a mouse model of Alzheimer's disease," Journal of Neuroscience, vol. 32, no. 46, pp. 16129-16140, 2012.

[206] H.-S. Hong, J.-Y. Hwang, S.-M. Son, Y.-H. Kim, M. Moon, and M.-J. Inhee, "FK506 reduces amyloid plaque burden and induces MMP-9 in A $\beta$ PP/PS1 double transgenic mice," Journal of Alzheimer's Disease, vol. 22, no. 1, pp. 97-105, 2010.

[207] E. Hudry, H.-Y. Wu, M. Arbel-Ornath et al., "Inhibition of the NFAT pathway alleviates amyloid beta neurotoxicity in a mouse model of Alzheimer's disease," Journal of Neuroscience, vol. 32, no. 9, pp. 3176-3192, 2012.

[208] S. Kim, R. F. Titcombe, H. Zhang et al., "Network compensation of cyclic GMP-dependent protein kinase II knockout in the hippocampus by $\mathrm{Ca}^{2+}$-permeable AMPA receptors," Proceedings of the National Academy of Sciences of the United States of America, vol. 112, no. 10, pp. 3122-3127, 2015.

[209] M. I. K. Hamad, A. Jack, O. Klatt et al., “Type I TARPs promote dendritic growth of early postnatal neocortical pyramidal cells in organotypic cultures," Development, vol. 141, no. 8, pp. 17371748, 2014.

[210] M. Itakura, I. Watanabe, T. Sugaya, and M. Takahashi, "Direct association of the unique C-terminal tail of transmembrane AMPA receptor regulatory protein $\gamma-8$ with calcineurin," FEBS Journal, vol. 281, no. 5, pp. 1366-1378, 2014.

[211] D. M. MacLean, S. S. Ramaswamy, M. Du, J. R. Howe, and V. Jayaraman, "Stargazin promotes closure of the AMPA receptor ligand-binding domain," The Journal of General Physiology, vol. 144, no. 6, pp. 503-512, 2014.

[212] O. R. Rana, E. Saygili, C. Meyer et al., "Regulation of nerve growth factor in the heart: the role of the calcineurin-NFAT pathway," Journal of Molecular and Cellular Cardiology, vol. 46, no. 4, pp. 568-578, 2009.

[213] E. Saygili, O. R. Rana, C. Günzel et al., "Rate and irregularity of electrical activation during atrial fibrillation affect myocardial NGF expression via different signalling routes," Cellular Signalling, vol. 24, no. 1, pp. 99-105, 2012.

[214] T. Minami, K. Yano, M. Miura et al., "The down syndrome critical region gene 1 short variant promoters direct vascular bed-specific gene expression during inflammation in mice," Journal of Clinical Investigation, vol. 119, no. 8, pp. 2257-2270, 2009.

[215] M. Sobrado, B. G. Ramirez, F. Neria et al., "Regulator of calcineurin 1 (Rcanl) has a protective role in brain ischemia/ reperfusion injury," Journal of Neuroinflammation, vol. 9, article 48, 2012.

[216] R. R. Baggott, A. Alfranca, D. López-Maderuelo et al., "Plasma membrane calcium ATPase isoform 4 inhibits vascular endothelial growth factor-mediated angiogenesis through interaction with calcineurin," Arteriosclerosis, Thrombosis, and Vascular Biology, vol. 34, no. 10, pp. 2310-2320, 2014.

[217] C.-J. Liu, Y.-C. Cheng, K.-W. Lee et al., "Lipopolysaccharide induces cellular hypertrophy through calcineurin/NFAT3 signaling pathway in H9c2 myocardiac cells," Molecular and Cellular Biochemistry, vol. 313, no. 1-2, pp. 167-178, 2008.

[218] S. Porta, S. A. Serra, M. Huch et al., "RCAN1 (DSCR1) increases neuronal susceptibility to oxidative stress: a potential pathogenic process in neurodegeneration," Human Molecular Genetics, vol. 16, no. 9, pp. 1039-1050, 2007.

[219] X. Sun, Y. Wu, B. Herculano, and W. Song, "RCAN1 overexpression exacerbates calcium overloading-induced neuronal apoptosis," PLoS ONE, vol. 9, no. 4, Article ID e95471, 2014.

[220] M. Perluigi, G. Pupo, A. Tramutola et al., "Neuropathological role of PI3K/Akt/mTOR axis in Down syndrome brain," Biochimica et Biophysica Acta-Molecular Basis of Disease, vol. 1842, no. 7, pp. 1144-1153, 2014.

[221] S.-Y. Shin, H. W. Yang, J.-R. Kim, W. D. Heo, and K.-H. Cho, "A hidden incoherent switch regulates RCAN1 in the calcineurinNFAT signaling network," Journal of Cell Science, vol. 124, no. 1, pp. 82-90, 2011.

[222] Y. Wu, P. T. T. Ly, and W. Song, "Aberrant expression of RCAN1 in Alzheimer's pathogenesis: a new molecular mechanism and a novel drug target," Molecular Neurobiology, vol. 50, no. 3, pp. 1085-1097, 2014.

[223] X. Liogier d'Ardhuy, J. O. Edgin, C. Bouis et al., "Assessment of cognitive scales to examine memory, executive function and 
language in individuals with down syndrome: implications of a 6-month observational study," Frontiers in Behavioral Neuroscience, vol. 9, article 300, 2015.

[224] F. Stagni, A. Giacomini, S. Guidi, E. Ciani, and R. Bartesaghi, "Timing of therapies for downsyndrome: the sooner, the better," Frontiers in Behavioral Neuroscience, vol. 9, article 265, 2015.

[225] E. H. Lee, S. S. Kim, S. Lee, K.-H. Baek, and S. R. Seo, "Pituitary Adenylate Cyclase-Activating Polypeptide (PACAP) targets down syndrome candidate region 1 (DSCR1/RCAN1) to control neuronal differentiation," The Journal of Biological Chemistry, vol. 290, no. 34, pp. 21019-21031, 2015.

[226] Y. Li, J. Wang, Y. Zhou, D. Li, and Z.-Q. Xiong, "Rcanl deficiency impairs neuronal migration and causes periventricular heterotopia," The Journal of Neuroscience, vol. 35, no. 2, pp. 610-620, 2015.

[227] V. Cavallucci, E. Bisicchia, M. T. Cencioni et al., "Acute focal brain damage alters mitochondrial dynamics and autophagy in axotomized neurons," Cell Death and Disease, vol. 5, article e1545, 2014

[228] B. M. Edens, N. Miller, and Y. Ma, "Impaired autophagy and defective mitochondrial function: converging paths on the road to motor neuron degeneration," Frontiers in Cellular Neuroscience, vol. 10, article 44, 2016.

[229] S. Ghavami, S. Shojaei, B. Yeganeh et al., "Autophagy and apoptosis dysfunction in neurodegenerative disorders," Progress in Neurobiology, vol. 112, pp. 24-49, 2014.

[230] V. G. Yerra and A. Kumar, "Adenosine monophosphateactivated protein kinase abates hyperglycaemia-induced neuronal injury in experimental models of diabetic neuropathy: effects on mitochondrial biogenesis, autophagy and neuroinflammation," Molecular Neurobiology, 2016.

[231] J. Park, D. G. Lee, B. Kim et al., "Iron overload triggers mitochondrial fragmentation via calcineurin-sensitive signals in HT-22 hippocampal neuron cells," Toxicology, vol. 337, pp. 39-46, 2015.

[232] J. Mu, Y. Song, J. Zhang, W. Lin, and H. Dong, "Calcium signaling is implicated in the diffuse axonal injury of brain stem," International Journal of Clinical and Experimental Pathology, vol. 8, no. 5, pp. 4388-4397, 2015.

[233] B. Gabryel, A. Pudelko, J. Adamczyk, I. Fischer, and A. Malecki, "Calcineurin and Erk1/2-signaling pathways are involved in the antiapoptotic effect of cyclosporin A on astrocytes exposed to simulated ischemia in vitro," Naunyn-Schmiedeberg's Archives of Pharmacology, vol. 374, no. 2, pp. 127-139, 2006.

[234] B. Gabryel, M. Chalimoniuk, A. Stolecka, K. Waniek, J. Langfort, and A. Malecki, "Inhibition of arachidonic acid release by cytosolic phospholipase $\mathrm{A}_{2}$ is involved in the antiapoptotic effect of FK506 and cyclosporin A on astrocytes exposed to simulated ischemia in vitro," Journal of Pharmacological Sciences, vol. 102, no. 1, pp. 77-87, 2006.

[235] S. Jayanthi, X. Deng, B. Ladenheim et al., "Calcineurin/NFATinduced up-regulation of the Fas ligand/Fas death pathway is involved in methamphetamine-induced neuronal apoptosis," Proceedings of the National Academy of Sciences of the United States of America, vol. 102, no. 3, pp. 868-873, 2005.

[236] Y. Xu, L. Yang, S. Yu et al., "Spatiotemporal changes in NFATc4 expression of retinal ganglion cells after light-induced damage," Journal of Molecular Neuroscience, vol. 53, no. 1, pp. 69-77, 2014.

[237] C. Ni, Z. Li, M. Qian, Y. Zhou, J. Wang, and X. Guo, "Isoflurane induced cognitive impairment in aged rats through hippocampal calcineurin/NFAT signaling," Biochemical and Biophysical Research Communications, vol. 460, no. 4, pp. 889-895, 2015.
[238] Y. Yang, S. Song, H. Min, X. Chen, and Q. Gao, "STAT3 degradation mediated by calcineurin involved in the neurotoxicity of isoflurane," NeuroReport, vol. 27, no. 2, pp. 124-130, 2016.

[239] F. Neria, M. del Carmen Serrano-Perez, P. Velasco, K. Urso, P. Tranque, and E. Cano, "NFATc3 promotes $\mathrm{Ca}^{2+}$-dependent MMP3 expression in astroglial cells," Glia, vol. 61, no. 7, pp. 1052-1066, 2013.

[240] M. A. Sama, D. M. Mathis, J. L. Furman et al., "Interleukin-1 $\beta$ dependent signaling between astrocytes and neurons depends critically on astrocytic calcineurin/NFAT activity," Journal of Biological Chemistry, vol. 283, no. 32, pp. 21953-21964, 2008.

[241] K. Szydlowska, M. Zawadzka, and B. Kaminska, "Neuroprotectant FK506 inhibits glutamate-induced apoptosis of astrocytes in vitro and in vivo," Journal of Neurochemistry, vol. 99, no. 3, pp. 965-975, 2006.

[242] N. H. Shah, A. J. Schulien, K. Clemens et al., "Cyclin E1 regulates Kv2.1 channel phosphorylation and localization in neuronal ischemia," Journal of Neuroscience, vol. 34, no. 12, pp. 4326-4331, 2014.

[243] D. J. Gerber, D. Hall, T. Miyakawa et al., "Evidence for association of schizophrenia with genetic variation in the $8 \mathrm{p} 21.3$ gene, PPP3CC, encoding the calcineurin gamma subunit," Proceedings of the National Academy of Sciences of the United States of America, vol. 100, no. 15, pp. 8993-8998, 2003.

[244] T. Miyakawa, L. M. Leiter, D. J. Gerber et al., "Conditional calcineurin knockout mice exhibit multiple abnormal behaviors related to schizophrenia," Proceedings of the National Academy of Sciences of the United States of America, vol. 100, no. 15, pp. 8987-8992, 2003.

[245] C. A. Ogden, M. E. Rich, N. J. Schork et al., "Candidate genes, pathways and mechanisms for bipolar (manic-depressive) and related disorders: an expanded convergent functional genomics approach," Molecular Psychiatry, vol. 9, no. 11, pp. 1007-1029, 2004.

[246] N. Park, S. H. Juo, R. Cheng et al., "Linkage analysis of psychosis in bipolar pedigrees suggests novel putative loci for bipolar disorder and shared susceptibility with schipzoprenia," Molecular Psychiatry, vol. 9, no. 12, pp. 1091-1099, 2004.

[247] Y. Tian, I. Voineagu, S. P. Paşca et al., "Alteration in basal and depolarization induced transcriptional network in iPSC derived neurons from Timothy syndrome," Genome Medicine, vol. 6, no. 10, article 75, 2014.

[248] G. Quadrato, M. Y. Elnaggar, C. Duman, A. Sabino, K. Forsberg, and S. Di Giovanni, "Modulation of GABAA receptor signaling increases neurogenesis and suppresses anxiety through NFATc4," The Journal of Neuroscience, vol. 34, no. 25, pp. 8630 8645, 2014.

[249] C. Crozatier, S. Farley, I. M. Mansuy, S. Dumas, B. Giros, and E. T. Tzavara, "Calcineurin (protein phosphatase 2B) is involved in the mechanisms of action of antidepressants," Neuroscience, vol. 144, no. 4, pp. 1470-1476, 2007.

[250] S. L. Eastwood, P. W. J. Burnet, and P. J. Harrison, “Decreased hippocampal expression of the susceptibility gene PPP3CC and other calcineurin subunits in schizophrenia," Biological Psychiatry, vol. 57, no. 7, pp. 702-710, 2005.

[251] N. Kozlovsky, E. Scarr, B. Dean, and G. Agam, "Postmortem brain calcineurin protein levels in schizophrenia patients are not different from controls," Schizophrenia Research, vol. 83, no. 2-3, pp. 173-177, 2006.

[252] H. K. Manji, I. I. Gottesman, and T. D. Gould, "Signal transduction and genes-to-behaviors pathways in psychiatric diseases," Science's STKE, vol. 2003, no. 207, article pe49, 2003. 
[253] W. J. Rushlow, Y. H. Seah, D. J. Belliveau, and N. Rajakumar, "Changes in calcineurin expression induced in the rat brain by the administration of antipsychotics," Journal of Neurochemistry, vol. 94, no. 3, pp. 587-596, 2005.

[254] T. D. McClure-Begley, S. R. Grady, M. J. Marks, A. C. Collins, and J. A. Stitzel, "Presynaptic GABAB autoreceptor regulation of nicotinic acetylcholine receptor mediated $\left[{ }^{3} \mathrm{H}\right]-\mathrm{GABA}$ release from mouse synaptosomes," Biochemical Pharmacology, vol. 91, no. 1, pp. 87-96, 2014.

[255] T.-T. Tzeng, H.-J. Tsay, L. Chang et al., "Caspase 3 involves in neuroplasticity, microglial activation and neurogenesis in the mice hippocampus after intracerebral injection of kainic acid," Journal of Biomedical Science, vol. 20, no. 1, article 90, 2013.

[256] H. Tokuoka, T. Hatanaka, D. Metzger, and H. Ichinose, "Nurr1 expression is regulated by voltage-dependent calcium channels and calcineurin in cultured hippocampal neurons," Neuroscience Letters, vol. 559, pp. 50-55, 2014.

[257] C. Freire-Cobo, G. Sierra-Paredes, M. Freire, and G. SierraMarcuño, "The calcineurin inhibitor Ascomicin interferes with the early stage of the epileptogenic process induced by Latrunculin A microperfusion in rat hippocampus," Journal of Neuroimmune Pharmacology, vol. 9, no. 5, pp. 654-667, 2014.

[258] G. Sierra-Paredes and G. Sierra-Marcuño, "Ascomycin and FK506: pharmacology and therapeutic potential as anticonvulsants and neuroprotectants," CNS Neuroscience and Therapeutics, vol. 14, no. 1, pp. 36-46, 2008.

[259] A. Vázquez-López, G. Sierra-Paredes, and G. Sierra-Marcuño, "Seizures induced by microperfusion of glutamate and glycine in the hippocampus of rats pretreated with latrunculin A," Neuroscience Letters, vol. 388, no. 2, pp. 81-85, 2005.

[260] M. L. Roberts-Crowley and A. R. Rittenhouse, "Characterization of ST14A cells for studying modulation of voltage-gated calcium channels," PLoS ONE, vol. 10, no. 7, Article ID e0132469, 2015.

[261] I. O. Medvedev, A. J. Ramsey, S. T. Masoud et al., "D1 dopamine receptor coupling to PLC $\beta$ regulates forward locomotion in mice," The Journal of Neuroscience, vol. 33, no. 46, pp. 1812518133, 2013.

[262] L. D. Walensky and S. H. Snyder, "Inositol 1,4,5-trisphosphate receptors selectively localized to the acrosomes of mammalian sperm," Journal of Cell Biology, vol. 130, no. 4, pp. 857-869, 1995.

[263] G. Ramazzotti, A. Bavelloni, W. Blalock, M. Piazzi, L. Cocco, and I. Faenza, "BMP-2 induced expression of PLC $\beta 1$ that is a positive regulator of osteoblast differentiation," Journal of Cellular Physiology, vol. 231, no. 3, pp. 623-629, 2016.

[264] J. Brotchie and P. Jenner, "New approaches to therapy," International Review of Neurobiology, vol. 98, pp. 123-150, 2011.

[265] S. N. A. Bukhari and I. Jantan, "Synthetic curcumin analogs as inhibitors of $\beta$-amyloid peptide aggregation: potential therapeutic and diagnostic agents for Alzheimer's disease," MiniReviews in Medicinal Chemistry, vol. 15, no. 13, pp. 1110-1121, 2015.

[266] J. Segura-Aguilar, P. Muñoz, and I. Paris, "Aminochrome as new preclinical model to find new pharmacological treatment that stop the development of Parkinsons disease," Current Medicinal Chemistry, vol. 23, no. 4, pp. 346-359, 2016.

[267] L. Brandenstein, M. Schweizer, J. Sedlacik, J. Fiehler, and S. Storch, "Lysosomal dysfunction and impaired autophagy in a novel mouse model deficient for the lysosomal membrane protein Cln7," Human Molecular Genetics, vol. 25, no. 4, pp. 777791, 2016.
[268] G. Natale, P. Lenzi, G. Lazzeri et al., "Compartment-dependent mitochondrial alterations in experimental ALS, the effects of mitophagy and mitochondriogenesis," Frontiers in Cellular Neuroscience, vol. 9, article 434, 2015.

[269] D. M. Samy, C. A. Ismail, R. A. Nassra, T. M. Zeitoun, and A. M. Nomair, "Downstream modulation of extrinsic apoptotic pathway in streptozotocin-induced Alzheimer's dementia in rats: erythropoietin versus curcumin," European Journal of Pharmacology, vol. 770, pp. 52-60, 2016. 


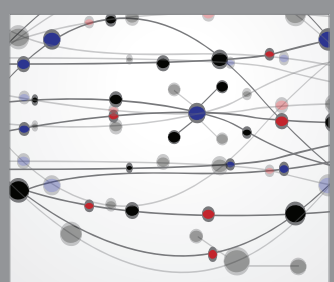

The Scientific World Journal
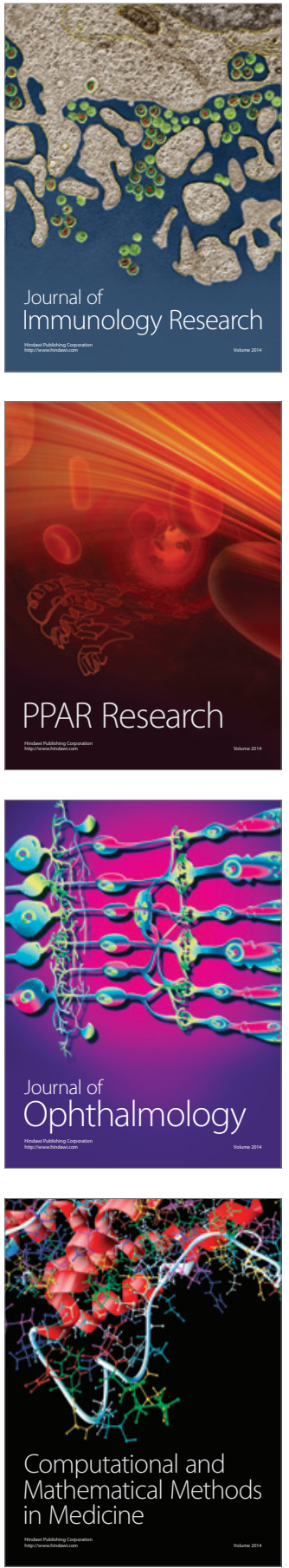

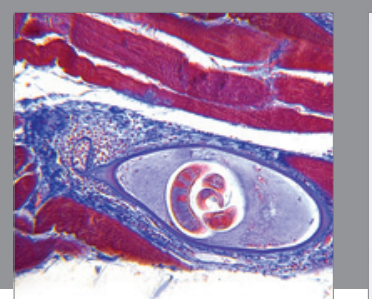

Gastroenterology Research and Practice

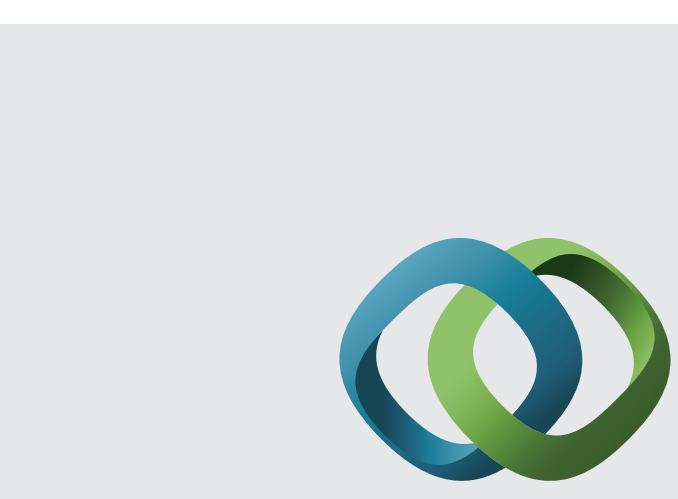

\section{Hindawi}

Submit your manuscripts at

http://www.hindawi.com
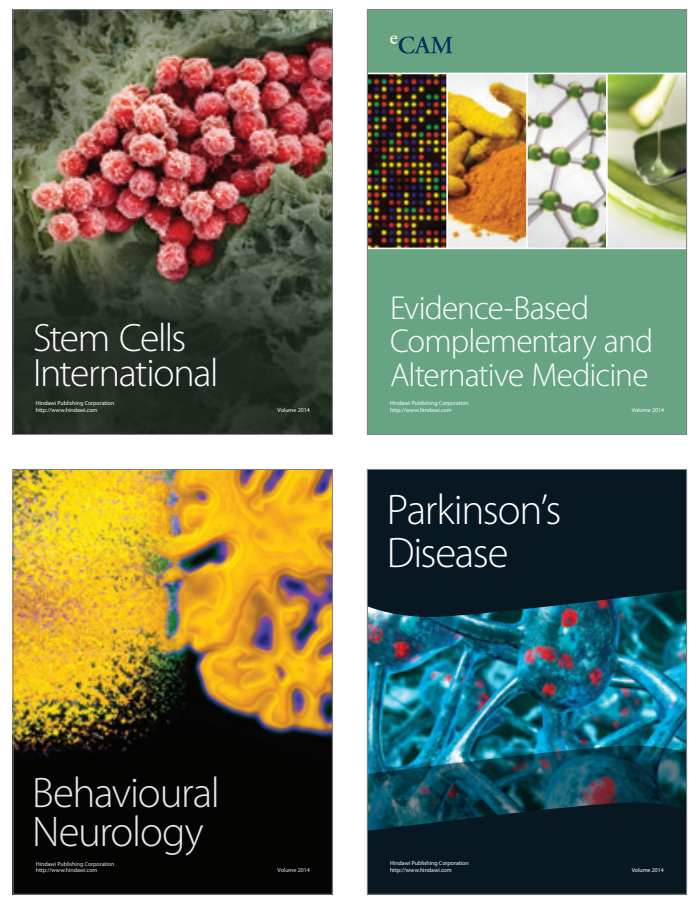
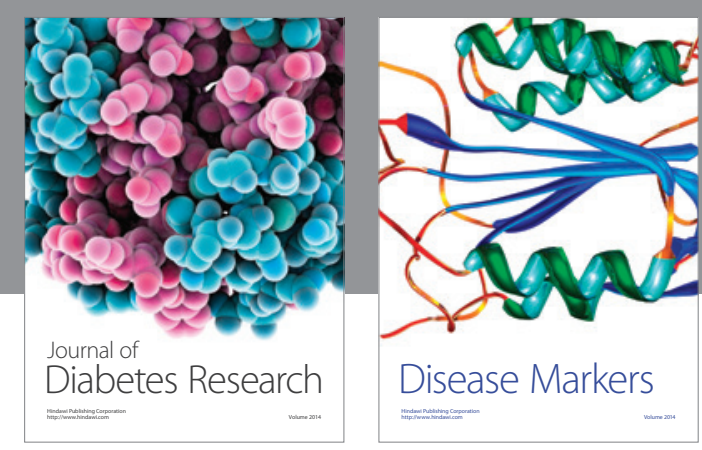

Disease Markers
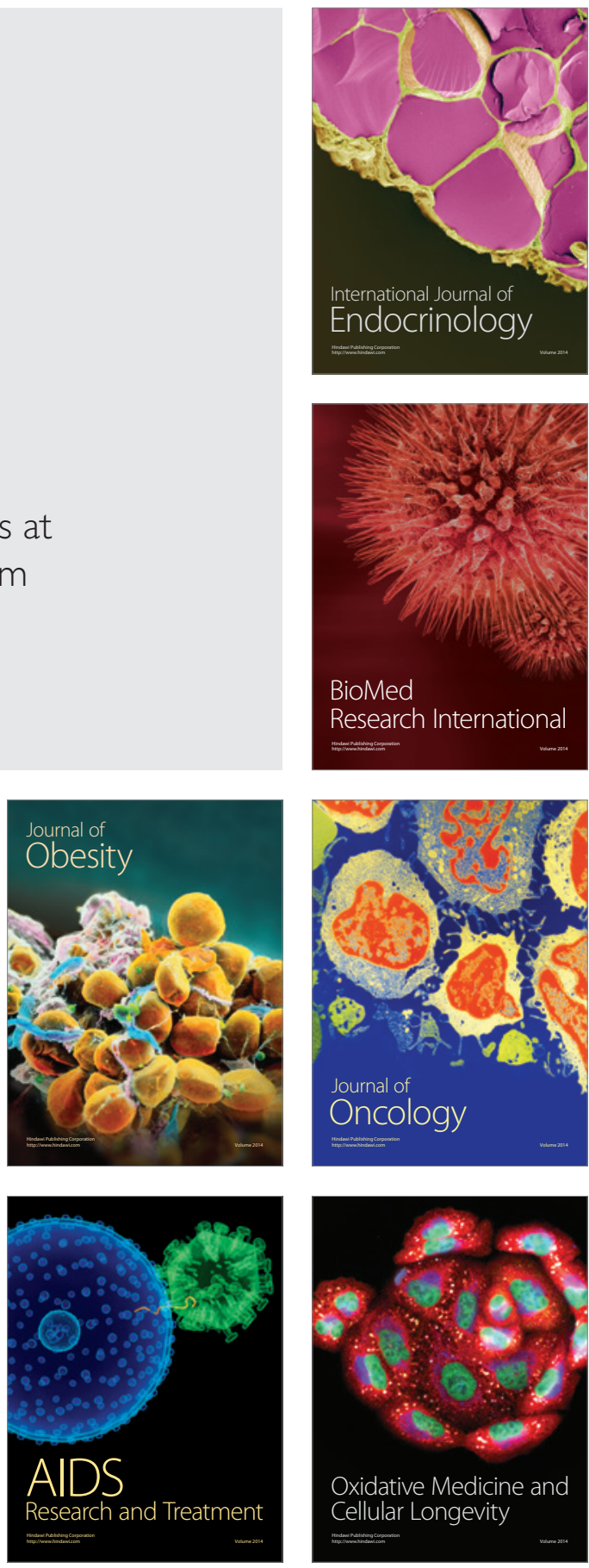